\title{
Regional Eta model experiments: SALLJEX and MCS development
}

\author{
José Roberto Rozante ${ }^{1}$ and Iracema Fonseca de Albuquerque Cavalcanti ${ }^{1}$ \\ Received 2 November 2007; revised 23 April 2008; accepted 20 May 2008; published 3 September 2008.
}

[1] The rainfall regime over La Plata Basin is strongly influenced by Mesoscale Convective Systems (MCS) that develop during night time, associated with the Low-Level Jet (LLJ) to the east of the Andes. Since they are mesoscale systems, their predictability depends on the model resolution and its ability to represent the main features associated with their development. This study aimed at finding the best configuration of the regional Eta model applied to the region of frequent MCS development to the east of the Andes and to analyze the performance of the model at high resolution, simulating specific MCS cases using two convection schemes. Three experiments were performed for the South American LowLevel Jet Experiment (SALLJEX) period. Performance of the nonhydrostatic version was better than the hydrostatic version in cases of MCS development. The use of estimated instead of climatological soil moisture in the model, improved the results for several synoptic variables. Evaluation of the convection parameterization scheme indicated a better simulation using the Kain-Fritsch (KF) rather than the Betts-Miller-Janjic scheme in the cases of MCS development. Therefore the best configuration of the Eta model for the simulation of the MCS occurrences over northern Argentina is the nonhydrostatic version using KF convection scheme and estimated soil moisture. With this configuration, the model was able to simulate the precipitation and the main atmospheric characteristics associated with MCS development, such as the upper level jet, the LLJ, humidity, and associated mechanisms for ascending motion, 72 hours in advance.

Citation: Rozante, J. R., and I. F. A. Cavalcanti (2008), Regional Eta model experiments: SALLJEX and MCS development, J. Geophys. Res., 113, D17106, doi:10.1029/2007JD009566.

\section{Introduction}

[2] Mesoscale Convective Systems (MCS) that occur over Northern Argentina are associated with the Low-Level Jet (LLJ) and produce intense rainfall over La Plata basin [Vera et al., 2006; Salio et al., 2007]. They originate in small areas of convective activity, mainly at night time and cause heavy precipitation over northern Argentina as they develop into large convective complexes. During their propagation eastward, the MCS affect other regions of $\mathrm{La}$ Plata basin, such as Paraguay, Uruguay, and southern Brazil. Thus precipitation forecasts over these regions depend on the model's skill in representing these mesoscale systems and their formation and development.

[3] MCS cases associated with the LLJ to the east of Andes were observed over Northern Argentina during the South American Low-Level Jet Experiment (SALLJEX) [Vera et al., 2006]. During the experiment, monitoring of atmospheric conditions and numerical model forecasts provided useful information to flight mission campaigns that measured different thermodynamics variables at different atmospheric levels. Although models at that time could not

\footnotetext{
${ }^{1}$ Center for Weather Forecast and Climate Studies (CPTEC), National Institute for Space Research (INPE), São Paulo, Brazil.

Copyright 2008 by the American Geophysical Union. 0148-0227/08/2007JD009566\$09.00
}

forecast some of the MCS that occurred over the region, the forecasting of the LLJ was a guide for such development. Descriptions of SALLJEX are found in Vera et al. [2006] and Zipser et al. [2004]. In other experiments, the regional Eta model performed well in the identification of LLJ characteristics and associated diurnal precipitation variability [Vernekar et al., 2003]. Typical features of the LLJ were also obtained in experiments using the Eta model, including the moisture flux and moisture budget in La Plata basin associated with the flow at low levels [Saulo et al., 2000].

[4] To better reproduce mesoscale system conditions, high-resolution models are required. At resolution of a few kilometers the hydrostatic approximation is not valid any more, because the vertical motion associated with the small-scale convection is poorly represented by this approximation. The nonhydrostatic version has been suggested in model integrations at resolution smaller than $8 \mathrm{~km}$ [e.g., Kato and Saito, 1995]. Some meteorological centers, such as JMA (Japan Meteorological Agency) and NCEP (National Centers for Environmental Prediction) have used the operational regional models at 10 and at $8 \mathrm{~km}$ resolution with the nonhydrostatic version, and have obtained better results than with the hydrostatic version [e.g., Saito et al., 2006].

[5] Satellite images clearly show that MCS over Northern Argentina usually present strong convective activity. The representation of these systems in the forecast models relies 


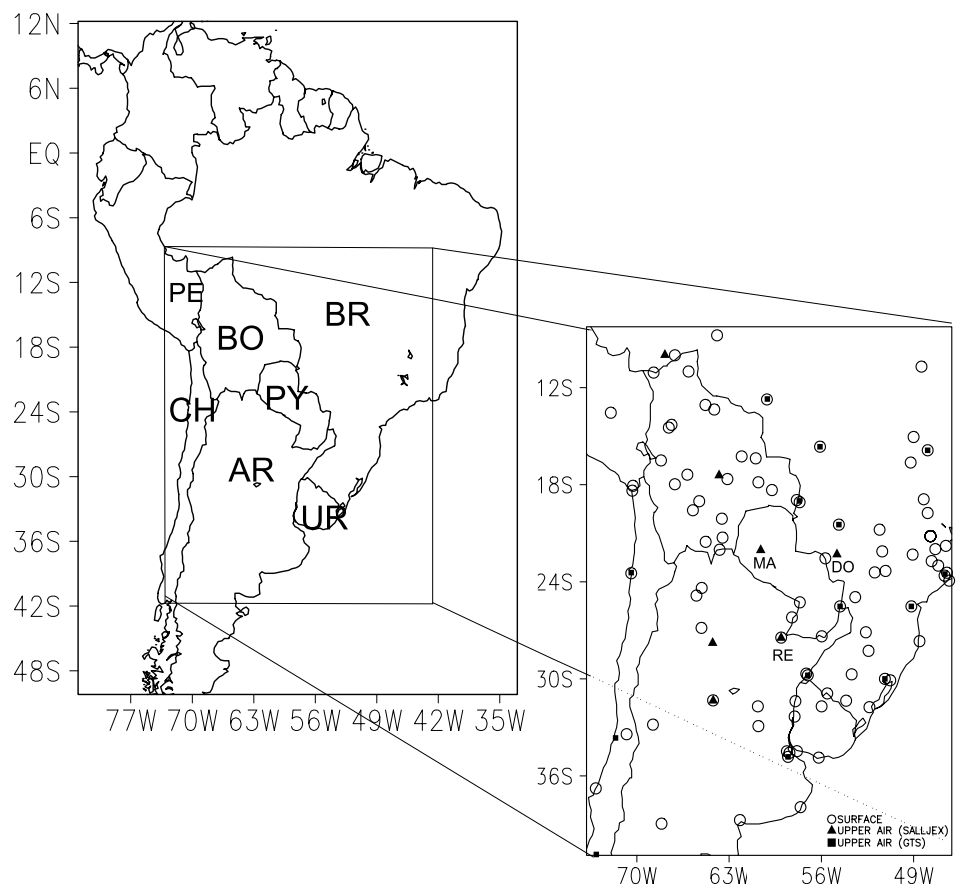

Figure 1. Integration domain and stations distribution in Brazil (BR), Argentina (AR), Paraguay (PY), Peru (PE), Bolívia (BO), and Chile (CH).

strongly on the convection scheme. Different schemes have been developed to parameterize convection in models, two of them have been used in the regional Eta model: Betts and Miller [1986] and Kain and Fritsch [1992]. Gochis et al. [2002] and Klausmann et al. [2002] tested different precipitation schemes' skill in a mesoscale model and found that the Kain and Fritsch (KF) scheme provided the best results, in agreement with Wang and Seaman [1997]. Other studies related to convection parameterization found that the performance of each scheme depends on the synoptic condition [Yang and Tung, 2003], specific spatial resolution [Dudhia et al., 2000] and specific region [Pielke, 2002]. Studies over South America using the regional Eta model with the BMJ convection parameterization were developed by Saulo et al. [2000] and Seluchi and Chou [2001]. The KF scheme has not been used in studies over the region. Therefore an evaluation of its behavior, mainly in the region of MCS occurrence, is relevant in forecasting studies.

[6] Soil moisture impact on model precipitation has been discussed in several studies, such as Viterbo and Beljaars [1995]; de Gonçalves et al. [2006]. Soil moisture content is one of the most important elements in the latent and sensible heat transfer [Sellers et al., 1989]. It affects the surface albedo and consequently the solar radiation input [McCumber and Pielke, 1981]. Additionally, soil moisture is important to the boundary layer structure and potential for establishment of convection [McCumber and Pielke, 1981; Segal et al., 1995]. Climatological values of soil moisture [Willmott et al., 1985] have been applied, in the beginning of the integration in most of global and regional models. Even with calculations of soil moisture during the integration by a surface scheme, this approach may be inadequate in anomalous cases such as very wet or very dry conditions. Therefore the use of estimated soil moisture to initialize the surface conditions in atmospheric models seems to be more appropriate.

[7] This study aims to find the best configuration of the Eta regional model [Mesinger et al., 1988] to simulate MCS occurrence over Northern Argentina. In order to achieve this goal, several experiments were performed to analyze the model skill in a region of frequent MCS development, using different configurations: hydrostatic and nonhydrostatic versions, two convection parameterization schemes and estimated soil moisture initialization. These kinds of experiments have not been applied to this region before and it is useful to document the ability of different model versions in simulating features associated with MCS development in the region. These systems can produce heavy precipitation in a short time and, as observed in satellite images, sometimes they displace eastward affecting also other populated regions. Therefore a good prediction of these systems is desirable to provide information for civil defense activities. In addition, it is important to know if the model is able to represent the main atmospheric mechanisms associated with the MCS development. This paper is divided into five sections. Model description, experimental design, data sets and method are presented in section 2. In section 3, results of the experiments are analyzed through statistical

Table 1. Experimental Design Showing the Type (Hydrostatic $(\mathrm{H})$ and Nonhydrostatic (NH)), Convection Parameterization Scheme (Betts-Miller-Janjic (BMJ) and Kain-Fritsch (KF)), and Soil Moisture Initialization (Climatological (CM) and Estimated (EM))

\begin{tabular}{lccc}
\hline & TYPE & CONVECTION & SOIL MOISTURE \\
\hline EXP.1 & $\mathrm{H}$ and NH & BMJ & CM \\
EXP.2 & $\mathrm{H}$ & BMJ and KF & $\mathrm{CM}$ \\
EXP.3 & $\mathrm{H}$ & $\mathrm{KF}$ & EM and CM \\
EXP.4 & $\mathrm{NH}$ & $\mathrm{KF}$ & EM \\
\hline
\end{tabular}


Table 2. RMSE Error Calculated as the Mean of Errors at Each Vertical Level, During the SALLJEX Period, at 66 Hours Integration for Temperature, and Zonal and Meridional Winds at Mariscal $(*)$, Dourados $(* *)$, and Resistencia $(* * *)$

\begin{tabular}{|c|c|c|c|c|c|c|}
\hline & \multicolumn{2}{|c|}{ EXP1 } & \multicolumn{2}{|c|}{ EXP2 } & \multicolumn{2}{|c|}{ EXP3 } \\
\hline & $\mathrm{H}$ & $\mathrm{NH}$ & BMJ & KF & $\mathrm{CM}$ & EM \\
\hline $\mathrm{T}(*)$ & 0.66 & 0.65 & 3.17 & 4.68 & 1.14 & 0.90 \\
\hline $\mathrm{U}(*)$ & 1.91 & 1.77 & 1.91 & 2.37 & 2.37 & 2.10 \\
\hline $\mathrm{V}(*)$ & 3.17 & 2.95 & 0.66 & 1.14 & 4.68 & 3.86 \\
\hline $\mathrm{T}(* *)$ & 0.60 & 0.60 & 0.60 & 0.93 & 3.35 & 2.59 \\
\hline $\mathrm{U}(* *)$ & 3.15 & 2.95 & 3.15 & 3.41 & 3.41 & 3.28 \\
\hline $\mathrm{V}(* *)$ & 2.52 & 2.35 & 2.52 & 3.35 & 3.35 & 2.59 \\
\hline $\mathrm{T}(* * *)$ & 0.61 & 0.58 & 0.61 & 0.94 & 0.94 & 0.73 \\
\hline $\mathrm{U}(* * *)$ & 1.55 & 1.48 & 1.55 & 1.93 & 1.93 & 1.67 \\
\hline $\mathrm{V}(* * *)$ & 1.66 & 1.57 & 1.66 & 1.60 & 1.60 & 1.91 \\
\hline
\end{tabular}

indices. Model results of several MCS case simulations are discussed in section 4. Concluding remarks and final discussion are presented in section 5 .

\section{Methodology}

\subsection{Experimental Design}

[8] The experiments were performed using the regional Eta model (version "worketa") obtained from http://strc. comet.ucar.edu/model/wseta_installation.htm). This code is similar to the NCEP operational version but with a more friendly interface for performing experiments. This version is different from that available at the CPTEC site, especially concerning Betts-Miller convection parameters. This model has an E grid from Arakawa [Arakawa and Lamb, 1977] and vertical coordinate $\eta$ [Mesinger, 1984]. The splitexplicit technique is utilized during the integration [Gadd, 1978] and the turbulent processes are treated through the Mellor-Yamada scheme [Mellor and Yamada, 1982]. Parameterization of radiation was developed by Geophysical Fluid Dynamics Laboratory and follows Fells and Schwarzkopf [1975] for outgoing longwave radiation, and Lacis and Hansen [1974] for shortwave radiation. The

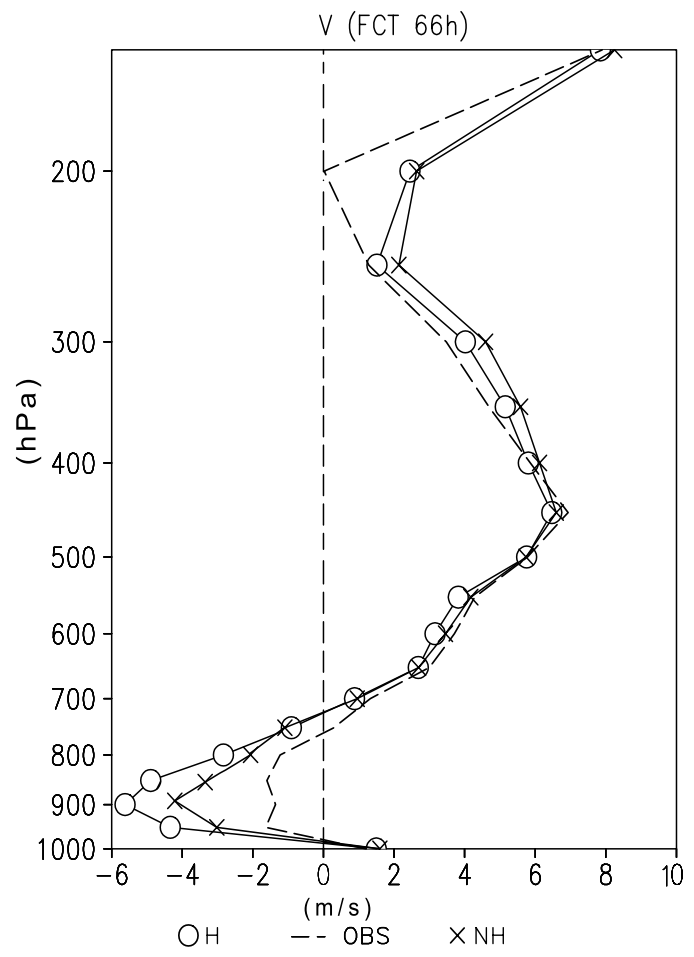

Figure 3. Vertical time mean profile, during SALLJEX, of meridional wind $(\mathrm{m} / \mathrm{s})$ at Resistência from OBS (observations) and $\mathrm{H}$ versus $\mathrm{NH}$. This profile was obtained taking the nearest model grid point to the station at $66-\mathrm{h}$ integration and averaging over the whole period.

surface processes are represented by the Noah scheme $[E k$ et al., 2003].

[9] The model was integrated with $10 \mathrm{~km}$ horizontal resolution and 38 vertical levels, using the domain in Figure 1, from second January to second February 2003, selected due to the large amount of observed data during the SALLJEX, which were used for model validation. Location

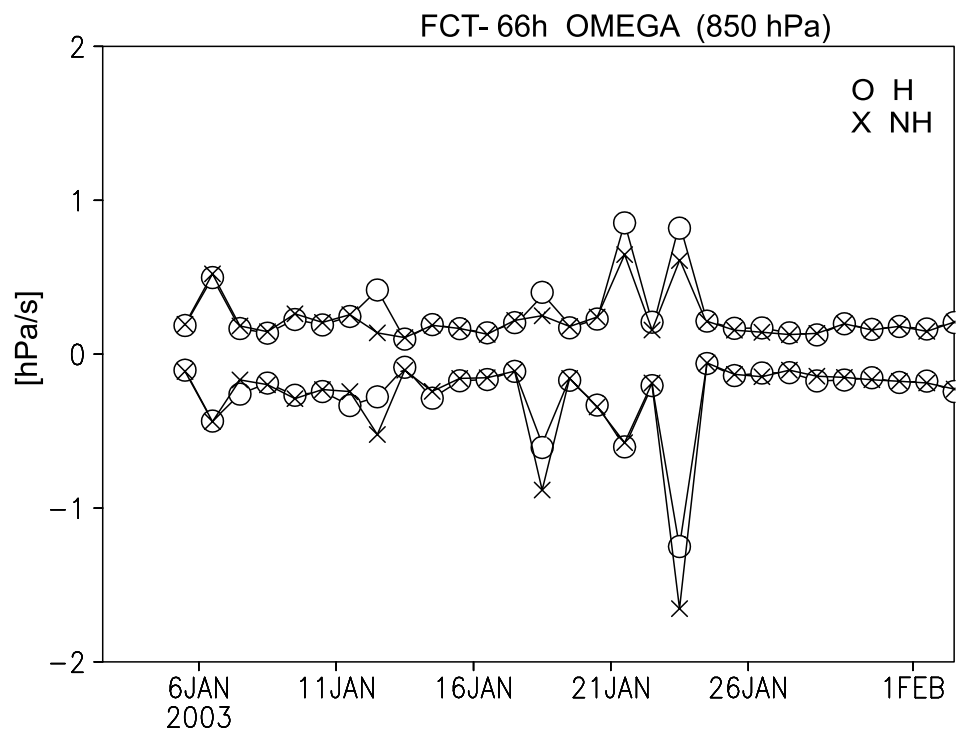

Figure 2. Positive and negative omega $(\mathrm{hPa} / \mathrm{s})$ at $66-\mathrm{h}$ integration averaged in the area of $\mathrm{MCS}$ occurrence during the period 2 January to 2 February 2003. 

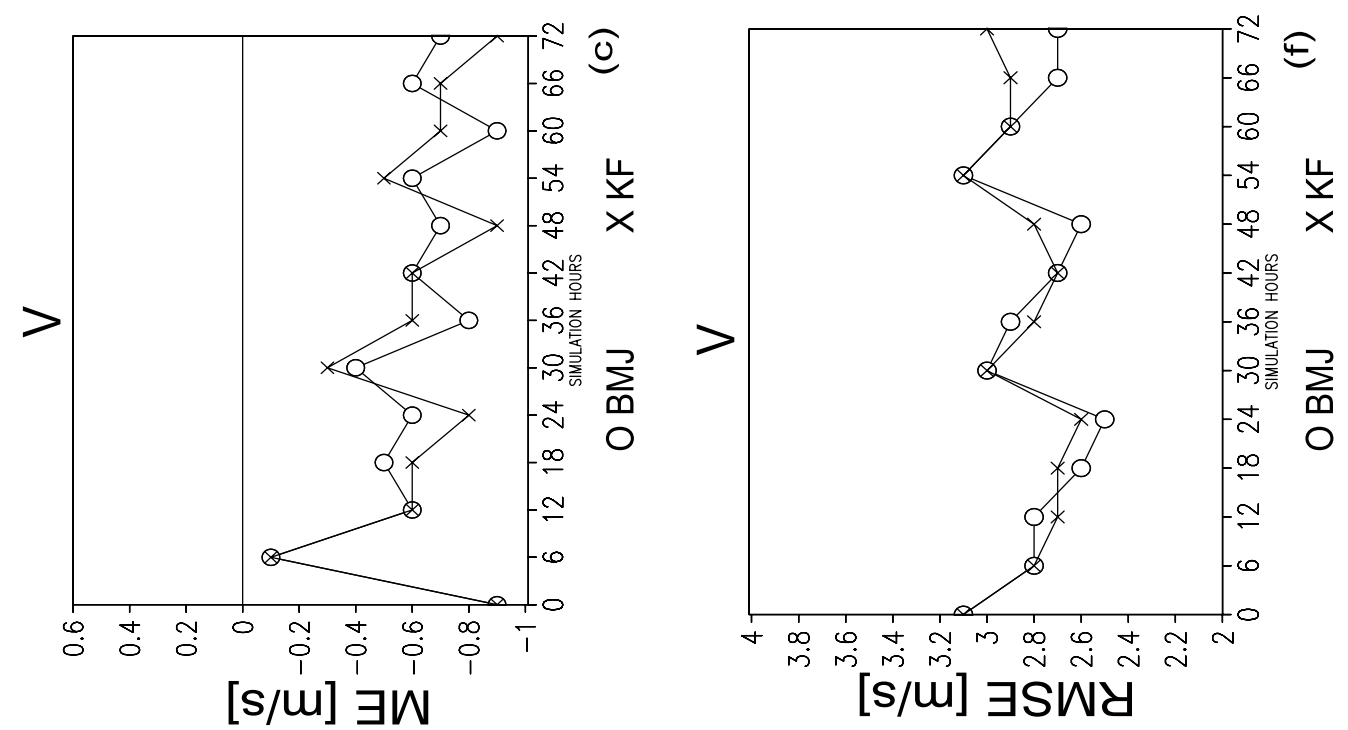

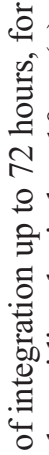

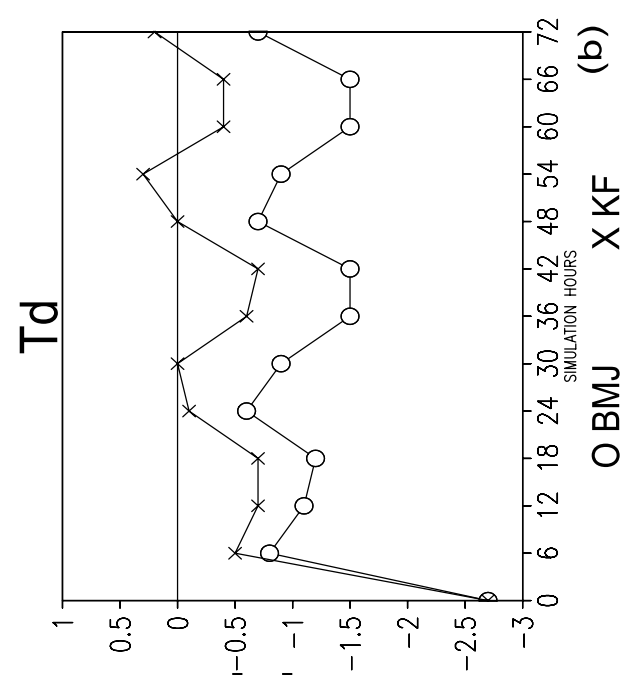

[s/u] $\exists S W Y$
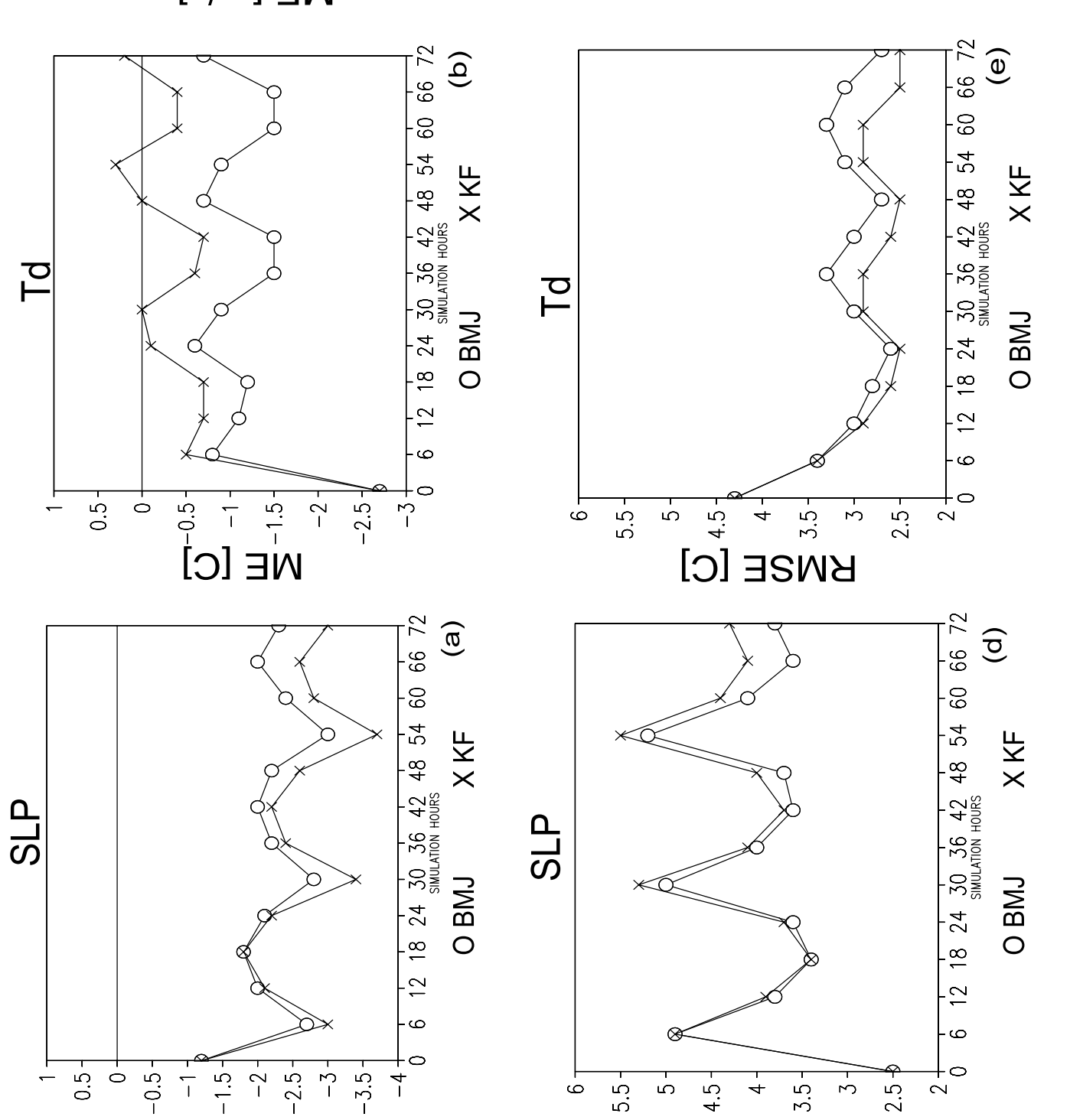

$\left[e_{d} 4\right] \exists W$

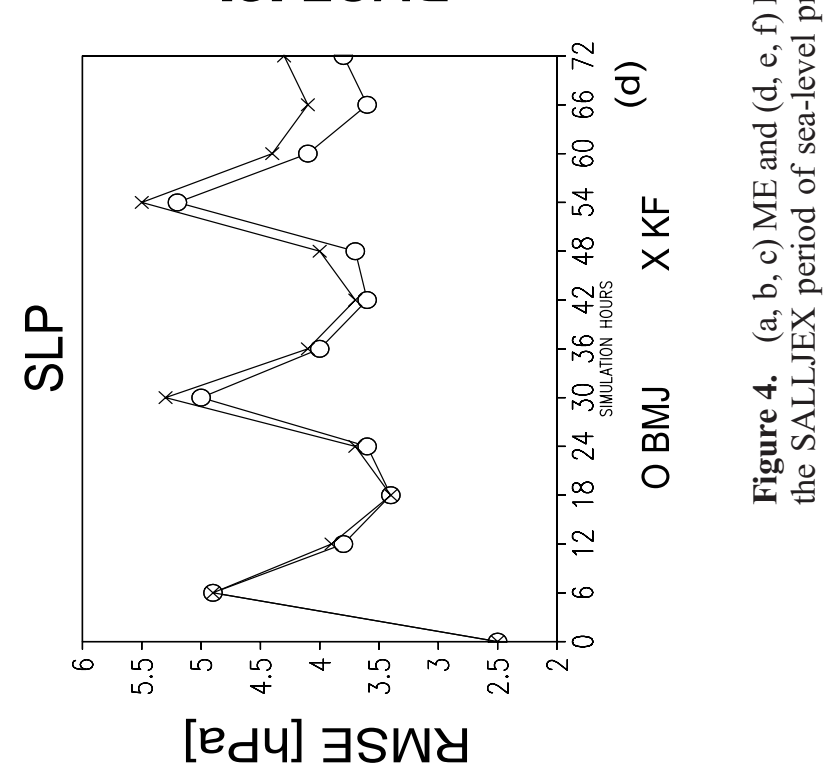



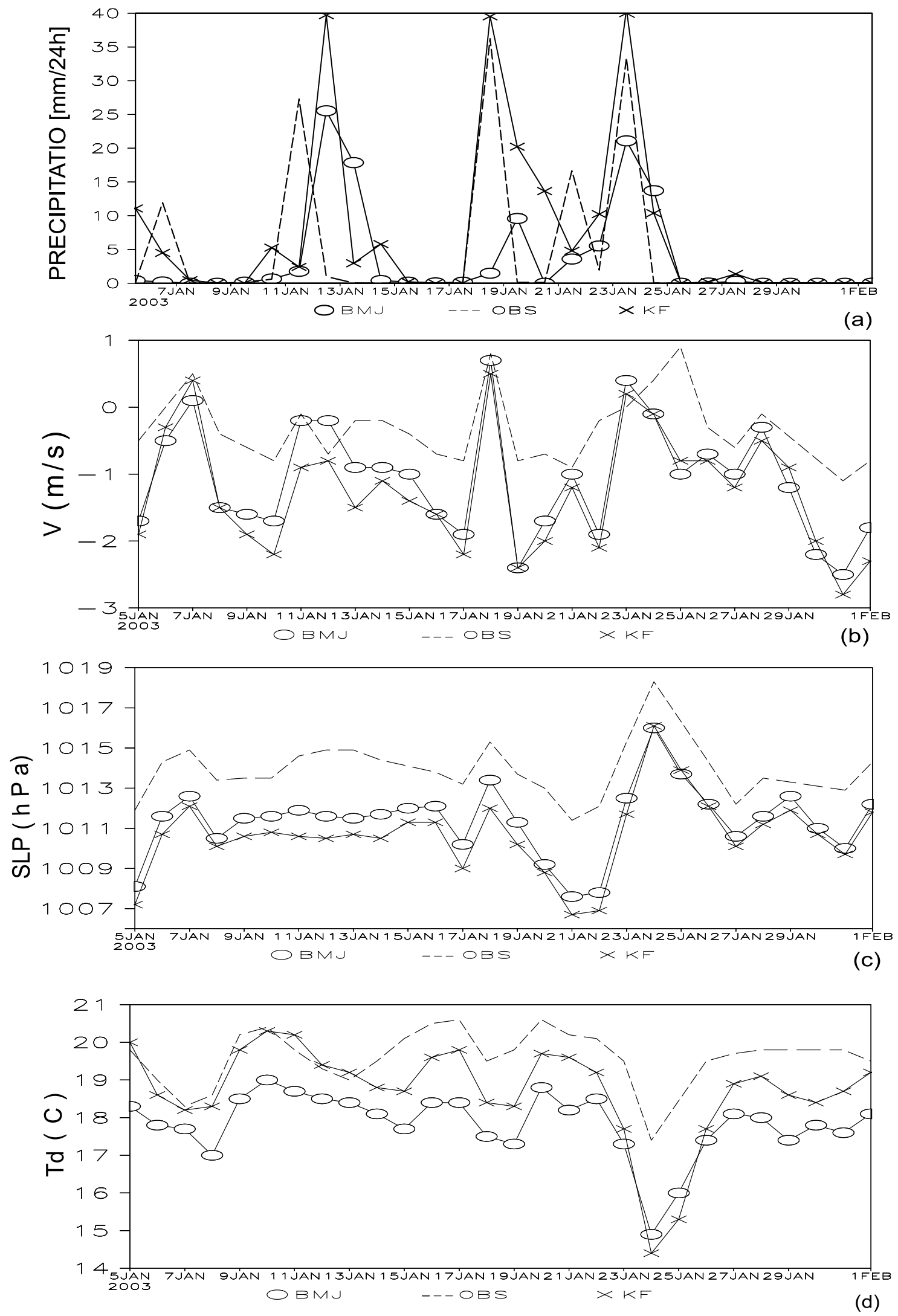

Figure 5. Daily evolution after 72 hours of integration of (a) accumulated ( $48-72 \mathrm{~h}$ ) precipitation over the frequent MCS development area $\left(35^{\circ} \mathrm{S}-20^{\circ} \mathrm{S}\right.$ and $\left.67.5^{\circ} \mathrm{W}-55^{\circ} \mathrm{W}\right)$, (b) meridional wind at $10 \mathrm{~m}(\mathrm{v})$, (c) sea-level pressure (SLP), and (d) dew point temperature at $2 \mathrm{~m}$ (Td) during the SALLJEX period. 


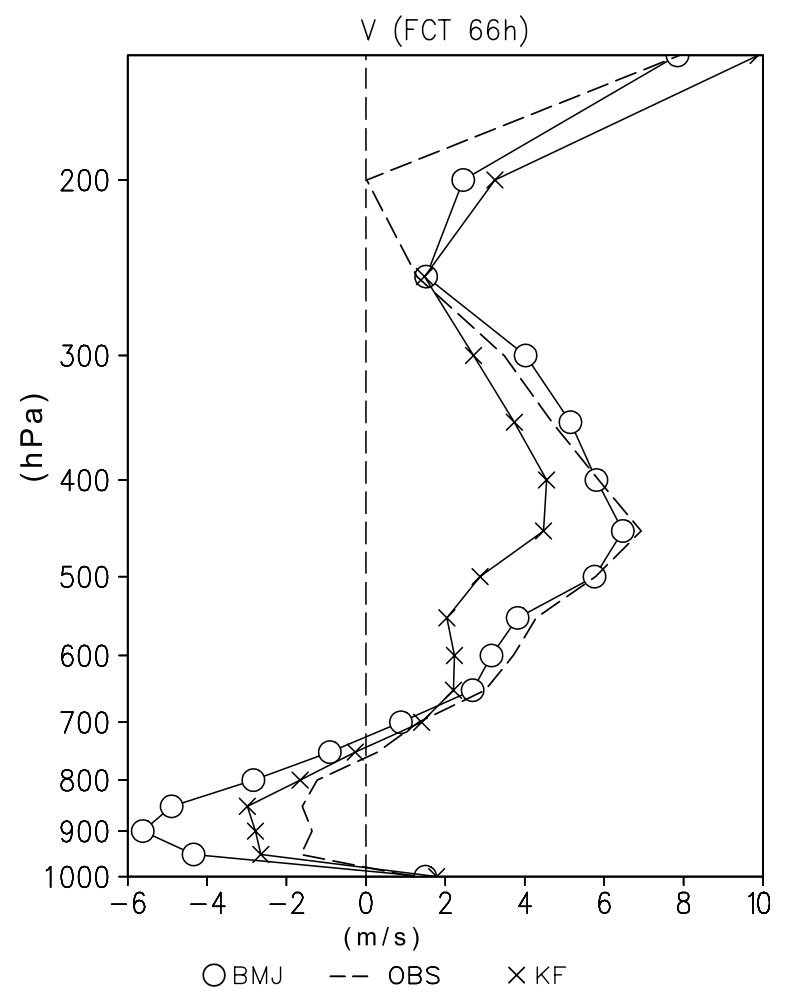

Figure 6. Vertical time mean profile, during SALLJEX, of meridional wind at Resistência, from observations and BMJ versus KF. This profile was obtained taking the nearest model grid point to the station at $66-\mathrm{h}$ integration and averaging over the whole period.

of soundings and surface data from that experiment are shown in Figure 1 and discussed in Cavalcanti and Herdies [2004]. The initial and lateral boundary conditions were obtained from analyses of the NCEP operational Global Data Assimilation System [Caplan et al., 1997] with spectral coefficients at T254 horizontal resolution and 64 vertical layers, every 6 hours. The model was initialized at 12:00 GMT - a time when the available observed data set is larger than at other hours, especially over South America - and integrated daily out to 72 hours, during 32 days. In the first 24 hours of integration there is an adjustment of the initial fields. Continuous operational evaluation in daily operational forecasts using this model at the Center for Weather Forecasts and Climate Studies/National Institute of Space Research (CPTEC/INPE) has shown similar performance for the $72 \mathrm{~h}$ and $48 \mathrm{~h}$ forecasts. Therefore forecasts obtained 3 days ahead are useful in detecting intense precipitation and in providing useful information to forecast users.

[10] Three kinds of experiments were performed using different configurations: the hydrostatic $(\mathrm{H})$ and nonhydrostatic (NH) versions, the Betts-Miller-Janjic (BMJ) [Betts and Miller, 1986; Janjic, 1994] and Kain-Fritsch (KF) [Kain and Fritsch, 1992] convection schemes, and the estimated (EM) versus climatological (CM) soil moisture (Table 1). A summary of the BMJ and KF schemes is given in Gochis et al. [2002]. The two convection schemes (BMJ and KF) were chosen due to their availability in the Eta model version used in this study. The evaluation of the experiments was carried out using 32 days of observed data from different sources: satellite, radiosondes, conventional and automatic stations. Satellite-estimated precipitation was obtained from the Tropical Rainfall Measurement Mission (TRMM), [Huffman et al., 1995] and 92 surface stations (SYNOP+METAR). Vertical profiles of temperature (T), meridional wind $(\mathrm{v})$ and zonal wind $(\mathrm{u})$ were obtained from radiosondes of 21 locations (Figure 1). Additionally, SALLJEX rain gauge data were included in the abovementioned data set. Satellite-estimated precipitation was combined with observations due to the small number of spatial precipitation data in the preferred region of MCS formation. The model performance was evaluated through statistical analyses of Mean Error (ME) and Root Mean Square Error (RMSE), [Fox, 1981], applied to sea level pressure (SLP), dew point temperature at $2 \mathrm{~m}(\mathrm{Td})$ and meridional wind at $10 \mathrm{~m}(\mathrm{v})$ at each 6 hours of integration up to 72 hours during the 32 days. These variables were chosen due to the availability of observed data at the surface stations and its relevance to MCS development. In addition, Equitable Threat Score (ETS), BIAS, Probability of Detection (POD) and False Alarm Ratio (FAR), [Baldwin and Kain, 2006] were calculated for precipitation over the northern Argentina area $\left(35^{\circ} \mathrm{S}-20^{\circ} \mathrm{S} ; 67.5^{\circ} \mathrm{W}-55^{\circ} \mathrm{W}\right)$. In order to remove the influence of bias on ETS analysis, a method proposed by Mesinger and Brill [2004] was used. The analyses were performed using the 48-72 hours accumulated precipitation for all days during the whole period. Simulated precipitation at 72 hours is defined as accumulated precipitation between 48-72 hours.

[11] Temperature, zonal and meridional wind vertical profiles were also analyzed in three locations as shown in Figure 1: Mariscal $\left(22.02^{\circ} \mathrm{S} ; 60.60^{\circ} \mathrm{W}\right)$ in Paraguay; Dourados $\left(22.28^{\circ} \mathrm{S} ; 54.82 \mathrm{~W}\right)$ in Brazil, and Resistencia $\left(27.44^{\circ} \mathrm{S} ; 59.05^{\circ} \mathrm{W}\right)$ in Argentina, denoted in Figure 1 by MA, DO, RE, respectively. ME and RMSE were calculated for the vertical structure of these variables. Time series of SLP, Td and v (average of all stations in Figure 1) and precipitation over northern Argentina, during the SALLJEX period, indicated the daily simulated variability compared to the observations. Vertical motion (omega) was also analyzed in the H-NH experiment. In order to discuss the conditions prior to the MCS development, some analyses were performed 6 hours earlier (at $66 \mathrm{~h}$ integration).

\subsection{MCS Case Simulations}

[12] An additional experiment to analyze the model results in specific MCS cases was included in Table 1. The two convection schemes (BMJ and KF) were tested in eight selected cases during spring, summer and autumn periods in this experiment. These cases were divided into two groups according to the MCS position and the location of the observed precipitation above $20 \mathrm{~mm}$ : (1) four cases that developed between latitudes $20^{\circ} \mathrm{S}-26^{\circ} \mathrm{S}$ (northern sector), and (2) four cases that occurred between latitudes $26^{\circ} \mathrm{S}-32^{\circ} \mathrm{S}$ (southern sector). The model was integrated 72 hours prior to each MCS development using the nonhydrostatic version and estimated soil moisture initialization in two experiments: one using BMJ and the other one using $\mathrm{KF}$ convection scheme $(10 \mathrm{~km}$ horizontal resolution and 38 vertical levels). In these simulations, the NCEP analysis was used as initial and lateral boundary conditions. MCS 

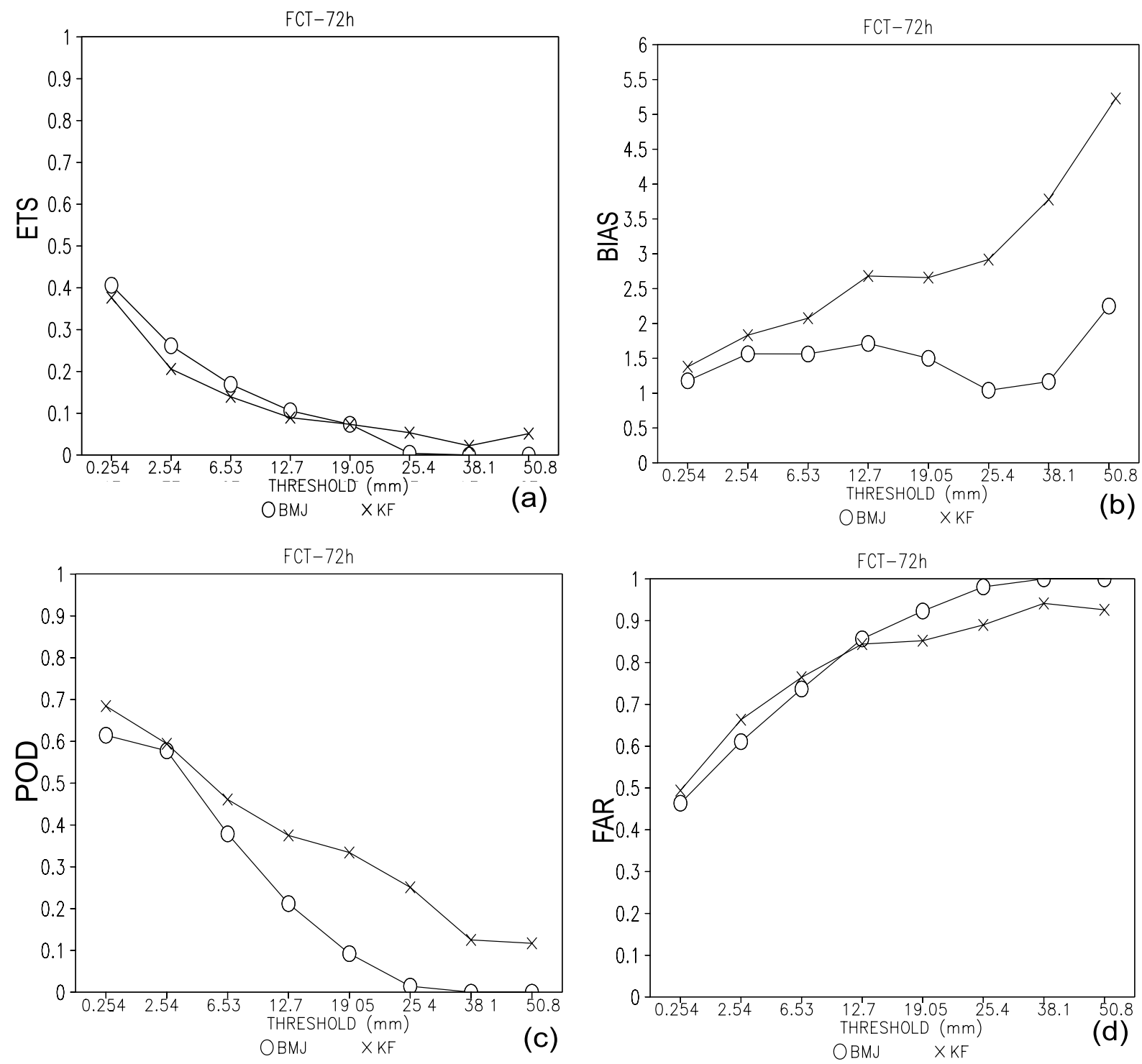

Figure 7. (a) ETS (without the bias influence), (b) BIAS, (c) POD e, and (d) FAR for accumulated 4872 hours precipitation simulations, calculated using station data.

cases that occurred during 2005-2006 were chosen to use the highest available resolution operational NCEP model at that time (T382L64). This differs from the resolution of NCEP initial conditions used during the SALLJEX period, which in 2003 was available at T254L64.

\section{Evaluation of Experiments}

[13] Three experiments were performed with the regional Eta Model to find the best configuration to apply in integrations of MCS cases that occur over northern Argentina.

\subsection{Hydrostatic Versus Nonhydrostatic}

[14] In this experiment, the model was integrated with the original convection scheme, BMJ, and climatological soil moisture to evaluate the performance of the hydrostatic $(\mathrm{H})$ and nonhydrostatic $(\mathrm{NH})$ versions. Both versions presented similar ME and RMSE in the spatial average analysis over the whole domain. However, in the vertical profile analysis of $\mathrm{T}, \mathrm{u}$ and $\mathrm{v}$ at specific locations (Mariscal, Dourados and Resistencia), RMSE were lower in the NH version (Table 2). An average of negative values (ascent) and positive values (subsidence) of omega at $850 \mathrm{hPa}$, in the area where there was development of two MCS during the SALLJEX, indicated differences between $\mathrm{H}$ and $\mathrm{NH}$ on specific days, including the days of those occurrences (18th and 23rd January 2003), with the strongest ascent in the NH version (Figure 2). An improvement using the NH version was also noted in the meridional wind at low levels in Resistencia, which is located close to the frequent MCS development area (Figure 3). The intensity of meridional wind is closer to the observations in $\mathrm{NH}$ than in $\mathrm{H}$. The reduction of horizontal wind in $\mathrm{NH}$ compared to $\mathrm{H}$ is related to the increase of vertical motion in that area during the days of MCS occurrence. Therefore the NH version should be used in cases of strong ascent and convection as in MCS episodes. 


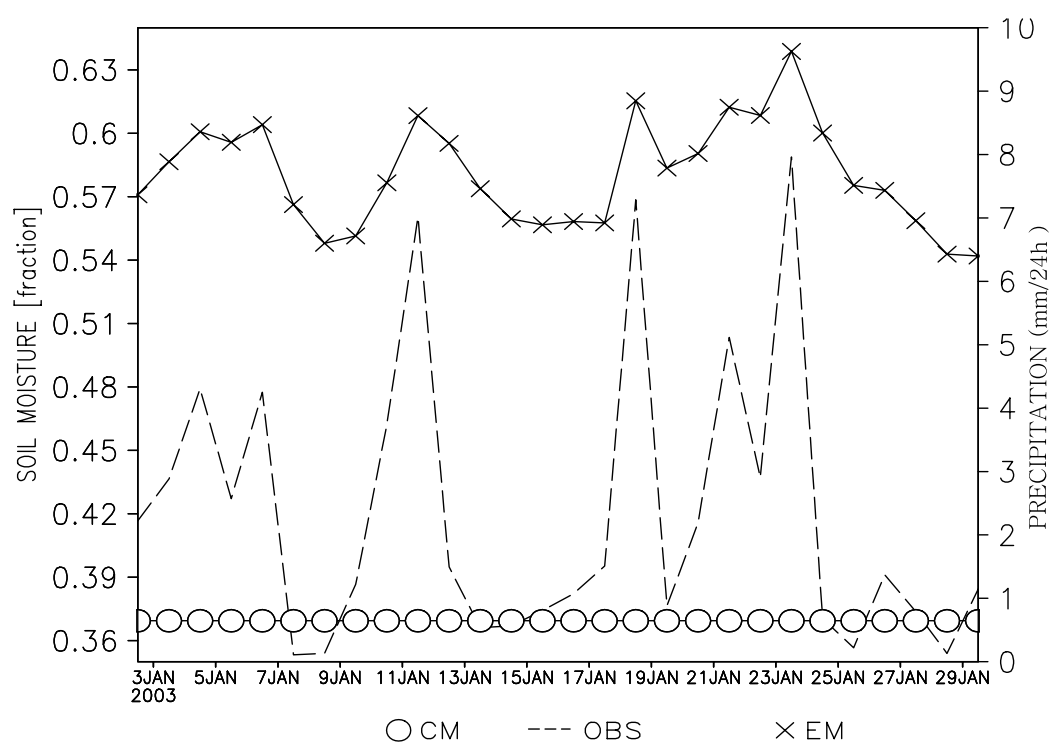

Figure 8. Time evolution of estimated and climatological soil moisture and the observed precipitation, averaged over the preferred MCS development area $\left(35^{\circ} \mathrm{S}-20^{\circ} \mathrm{S}\right.$ and $\left.67.5^{\circ} \mathrm{W}-55^{\circ} \mathrm{W}\right)$.

[15] Although the integration using the hydrostatic version on our computer system is twice as fast as the nonhydrostatic version, the reduction of errors and improvements, mainly in the meridional wind and vertical motion in the NH version may improve MCS simulations, due to the relation between the LLJ, convection and MCS development. The other experiments, for testing the convection scheme and the impact of estimated soil moisture during the SALLJEX period, were performed using the $\mathrm{H}$ version due to the integration efficiency, but the specific cases of MCS development were analyzed using the $\mathrm{NH}$ version (section 4).

\subsection{Betts-Miller-Janjic Versus Kain-Fritsch Convection Scheme}

[16] The convection parameterization was tested using Betts-Miller-Janjic and Kain-Fritsch schemes in the Eta $\mathrm{H}$ version with climatological soil moisture. Both versions presented negative ME of Sea Level Pressure (SLP) and meridional wind $(\mathrm{v})$, indicating that the model tends to intensify the lows and the northern wind component, behavior that was also found in the first experiment. The physical mechanism for the northern wind component intensification is likely related to the pressure lowering in the region. However, the ME and RMSE magnitudes were low, indicating a good model performance using both versions when the analysis is performed in a large area and over a long period (Figure 4). Differences of SLP and Dew point Temperature (Td) errors between the two versions increased with the integration time, but the variability during this time was similar in the two versions. Although the difference between the two versions was small, the BMJ version presented smaller errors of SLP but larger errors of $\mathrm{Td}$ than the KF version.

[17] For the meridional wind, the errors vary over the integration and at times the BMJ convection can have smaller or larger errors than the KF. Both versions present a diurnal cycle of SLP ME and RMSE, with the largest values at 18:00 GMT (after 6, 30, 54 hours of integration).
The largest differences between the model and the observation at this time, when there is maximum heating, is likely related to the different methods of sea level pressure reduction calculations, as discussed by Mesinger and Treadon [1995]. Since the domain has several locations in mountain regions, the sea level pressure reduction, which depends on the temperature and height, can present larger differences when the temperature is near its maximum. The highest Td errors were found at 00:00 GMT (after 36 and 60 hours integration), except in the beginning of integration, when the error was high due to the adjustments in the surface processes. An inspection of the humidity diurnal cycle shows maximum values between 18:00 and 00:00 GMT, closer to observations in KF than in BMJ, which produces a larger error at this time.

[18] Daily evolution of the 72-hour integration for the whole SALLJEX period is presented in Figure 5. The variability of SLP and Td was well simulated during the analyzed period by the two versions, and as mentioned before, the values were underestimated for pressure and $\mathrm{Td}$ but overestimated for the northerly component of the winds. Dew point temperatures were lower than observed in both versions, but the BMJ version presented $T_{d}$ much lower than the observed. The model was able to simulate the temperature well, using the two convection schemes (not shown), but $\mathrm{Td}$ values were closer to observations in the KF version. This suggests that the humidity field was better represented in the KF scheme, consistent with the analysis mentioned above. The meridional wind direction was well represented, and in some days, the model reached the observed values, although the observed meridional wind variability was not well represented by the model during the whole period (Figure $5 b$ ).

[19] The daily variability and intensity of simulated average precipitation over a region where two MCS developed during the SALLJEX period $\left(28 \mathrm{~S}^{\circ}-25^{\circ} \mathrm{S}\right.$ and $64^{\circ} \mathrm{W}-$ $60^{\circ} \mathrm{W}$ ) for the 72 hours of integration is shown in Figure 5a. The maximum precipitation observed on the 18th and 23rd was well captured by KF version while the BMJ simulates 


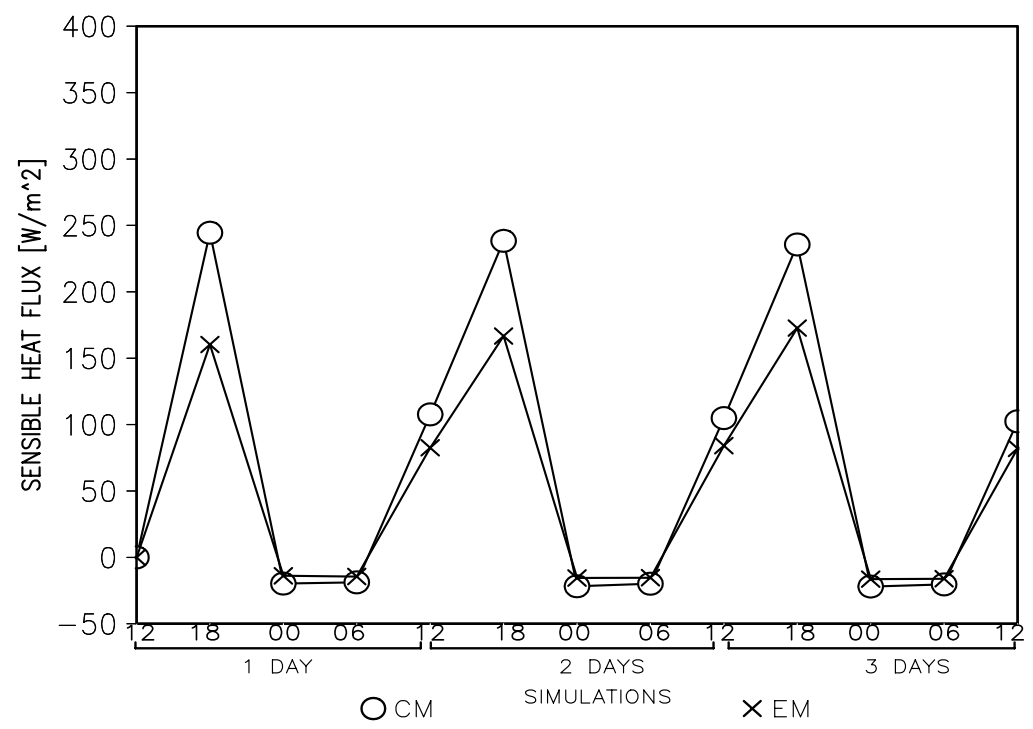

(a)

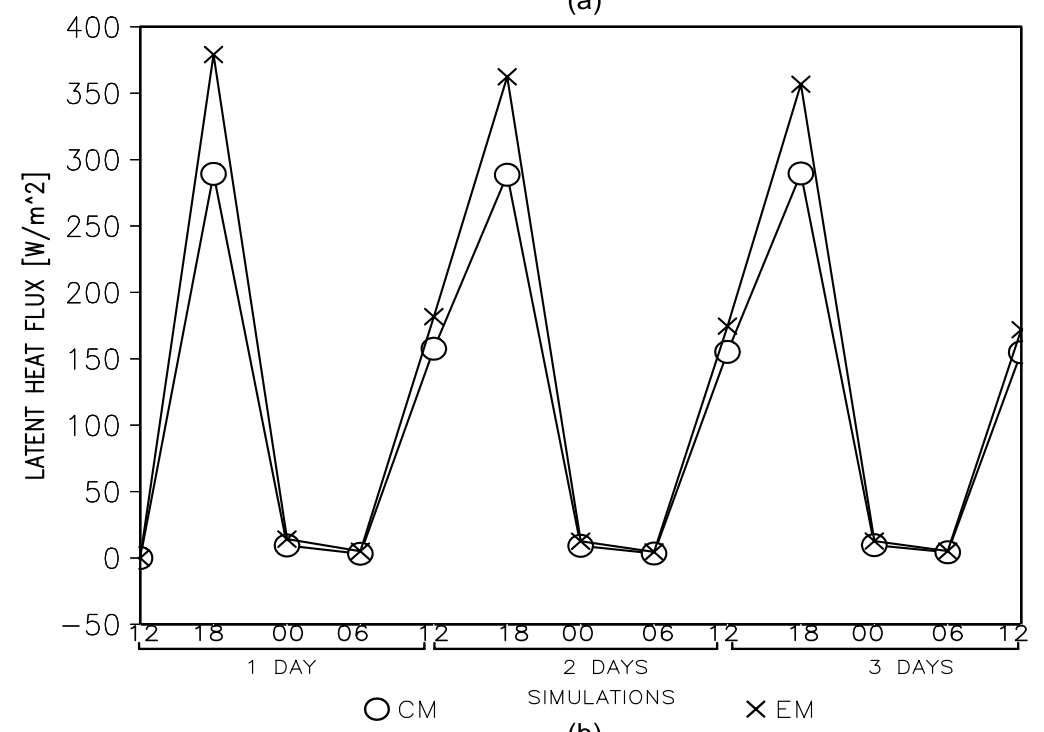

(b)

Figure 9. (a) Sensible and (b) latent heat flux mean, averaged over the preferred MCS development area $\left(35^{\circ} \mathrm{S}-20^{\circ} \mathrm{S}\right.$ e $\left.67.5^{\circ} \mathrm{W}-55^{\circ} \mathrm{W}\right)$.

lower values. The occurrence of these MCS over northern Argentina was associated with the LLJ [Vera et al., 2006; Rozante and Cavalcanti, 2006]. The northerly wind increase prior to the MCS development was also simulated in the whole domain, although with larger values than the observed. The two cases (18th and 23rd) were accompanied by a SLP reduction, previous to the maximum precipitation, followed by a SLP increase (Figure 5c), and corresponding southerly winds (Figure $5 \mathrm{~b}$ ), which indicated the influence of a frontal system's passage over the domain. The Td reduction associated with the frontal passage was also simulated in both cases (Figure 5d). The daily variability of all variables was well detected by the model in the 72-hour simulation.

[20] The RMSE averages of the vertical profile of $T, u$ and $\mathrm{v}$ at Mariscal, Dourados and Resistencia are presented in Table 2. In this case, when the analysis is performed for the whole period, the errors were lower in the BMJ experiment. During this period only two MCS developed over the region, and the inclusion of other days without strong convection is favorable to the BMJ scheme, as will be shown in the statistical precipitation analysis. However, in Resistencia, the RMSE of the meridional wind is slightly lower in KF than in BMJ. Northerly winds at low levels in this location have values close to observations in the $\mathrm{KF}$ version, and they are overestimated in the BMJ version (Figure 6). This impact on low-level meridional wind can be associated with vertical motion that is lower in BMJ than in $\mathrm{KF}$, and allows the increase of the horizontal wind.

[21] Statistical precipitation analyses (Figure 7) indicated by ETS showed better performance in BMJ than in KF, for light rains. However, for moderate to heavy rains, ETS values were higher in $\mathrm{KF}$ than in $\mathrm{BMJ}$, indicating that the KF scheme was better than the BMJ in the ability of obtaining the rainfall position for intense precipitation. Higher POD values for KF than BM, mainly for moderate 

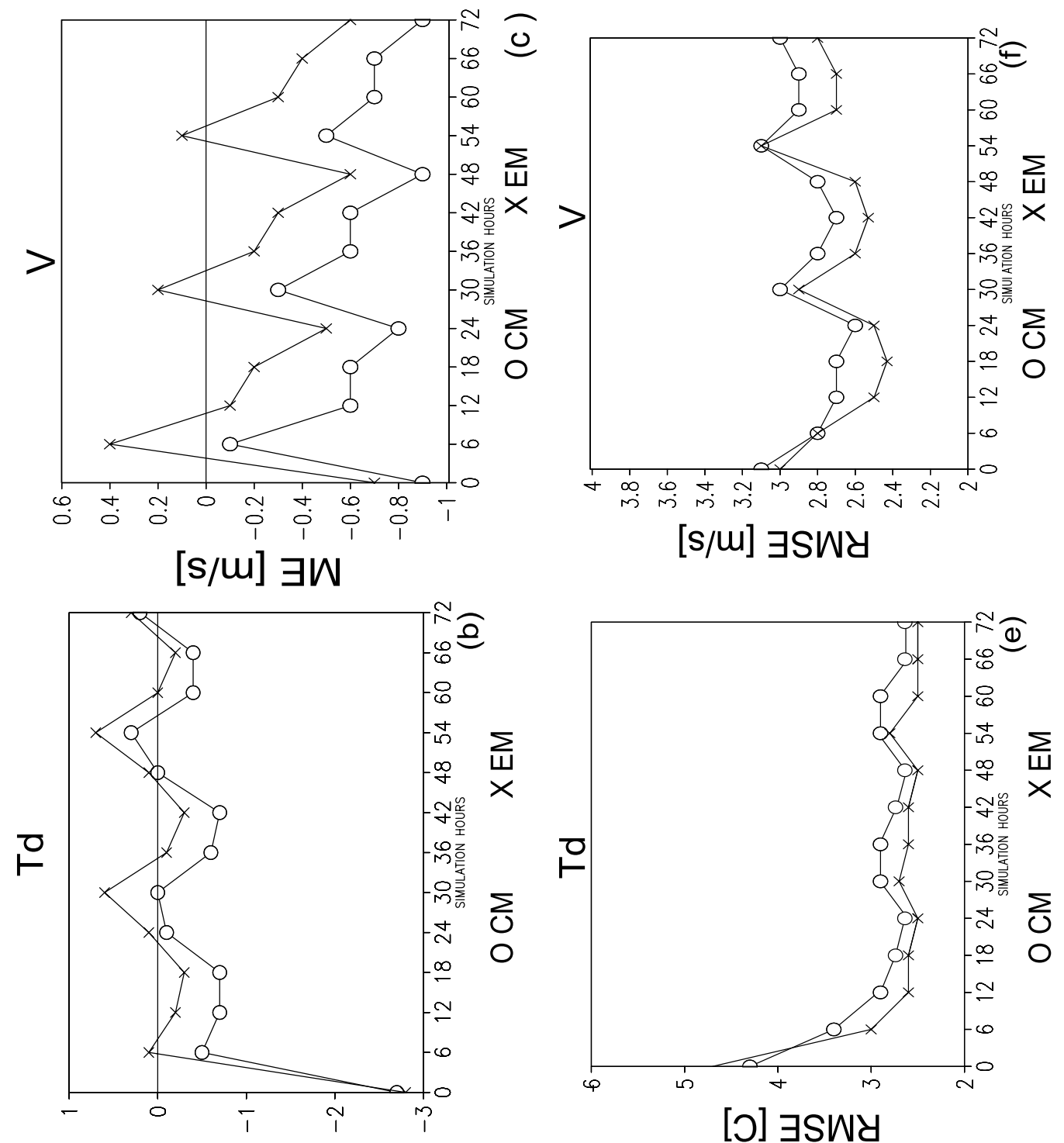

[อ] $\exists W$

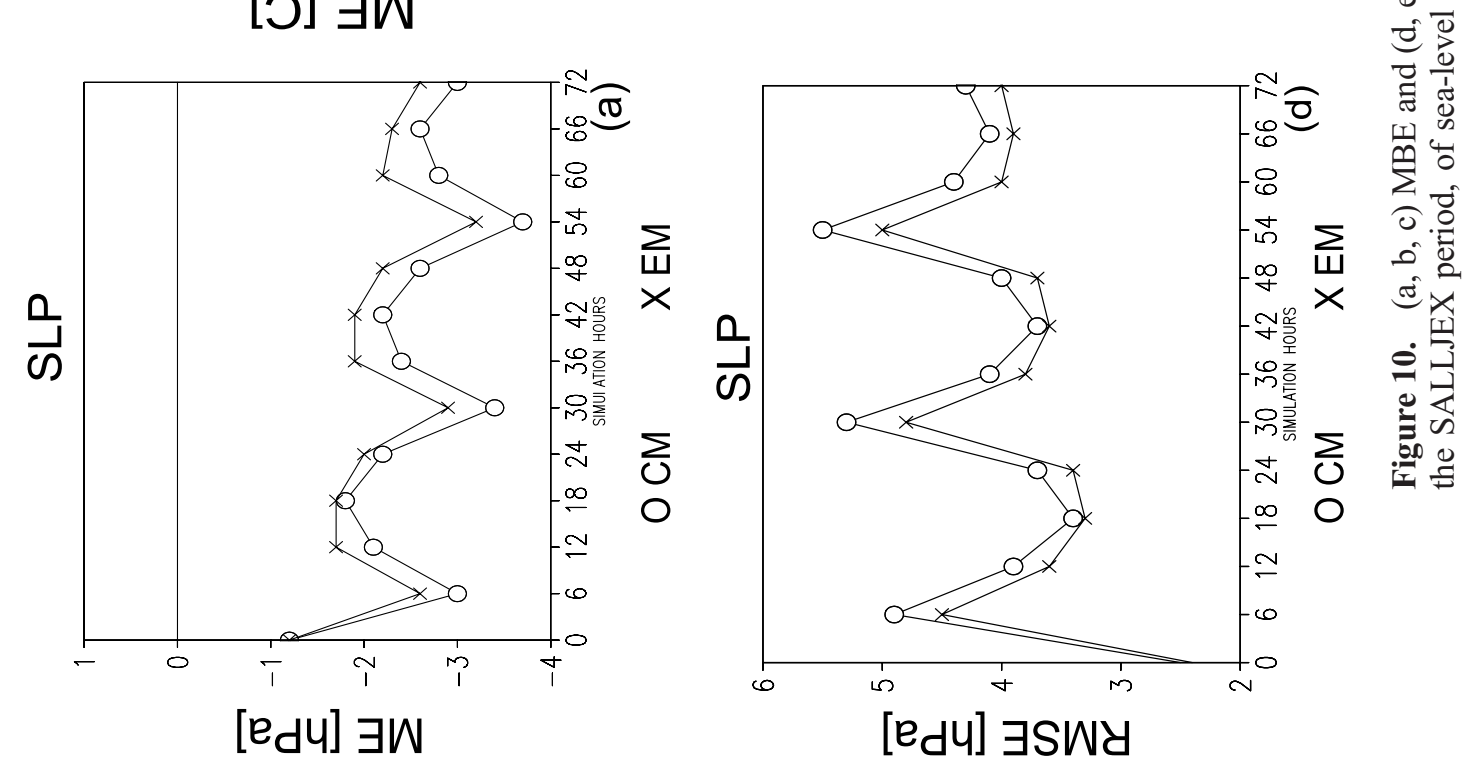




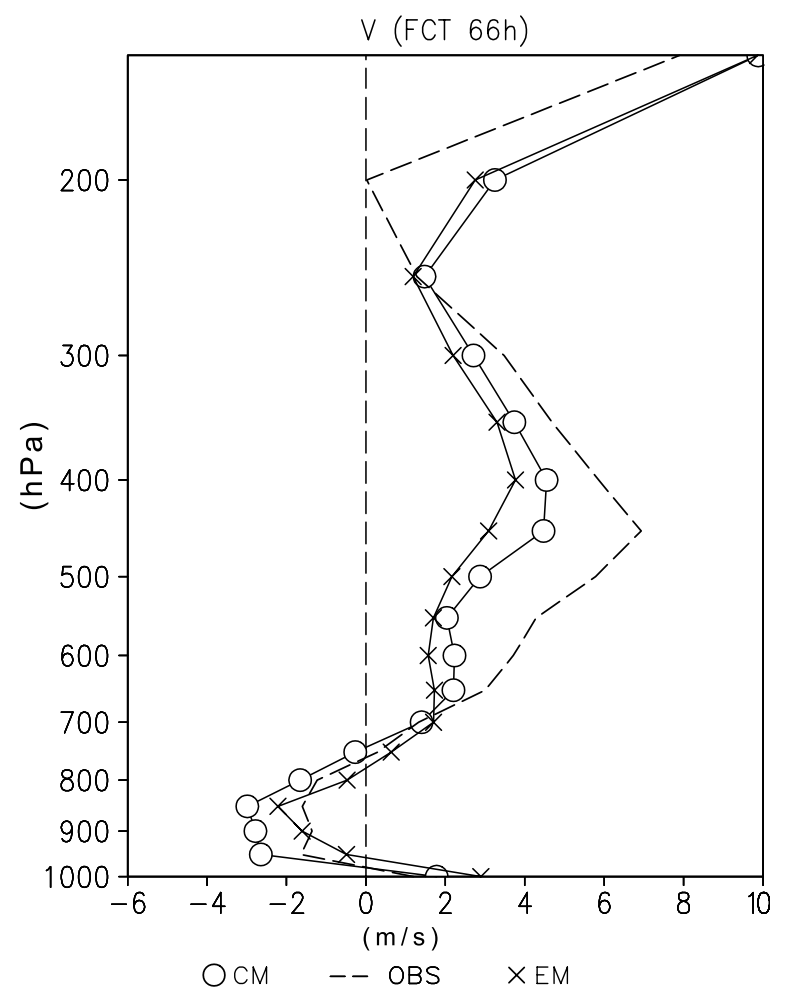

Figure 11. Vertical time mean profile, during SALLJEX, of meridional wind at Resistência, from OBS (observations) and CM versus EM. This profile was obtained taking the nearest model grid point to the station at 66-h integration and averaging over the whole period.

to heavy rains, indicated that this version was better to detect this rain category than BMJ. This characteristic was also noted in the FAR analysis. FAR values were higher for $\mathrm{BMJ}$ than $\mathrm{KF}$, indicating that BMJ simulated more cases of heavy precipitation that did not occur. On the other hand, $\mathrm{BMJ}$ presented lower values than KF for light rains.

[22] In cases of heavy rain, entraining/detraining air to and from convective clouds, which is considered in the $\mathrm{KF}$ scheme, is important to the simulated precipitation. Besides, the effects of moist updrafts and downdrafts are explicitly represented in KF while the BMJ scheme only considers an adjustment of the vertical temperature and moisture profile. From this experiment it is seen that the KF scheme should be used in cases of heavy precipitation concentrated in small areas, as in MCS occurrences, while BMJ presents better results for light rainfall in a large area.

\subsection{Climatological Versus Estimated Soil Moisture}

[23] This experiment was performed using the $\mathrm{KF}$ and $\mathrm{H}$ version of the Eta model, initialized with climatological soil moisture [Willmott et al., 1985] and with estimated soil moisture obtained from a technique developed by Gevaerd and Freitas [2006]. In this technique the estimated soil moisture is calculated using a hydrological model based on McCumber and Pielke [1981] initialized with precipitation from TRMM. The final product is a tridimensional field with three soil moisture vertical layers. The climatological or estimated soil moisture field is used as the initial surface boundary condition and, during the integration, this variable is calculated at each time step by the Noah surface scheme.

[24] The time evolution of estimated and climatological soil moisture, and the observed precipitation, averaged in the preferred $\mathrm{MCS}$ development area $\left(35^{\circ} \mathrm{S}-20^{\circ} \mathrm{S}\right.$; $\left.67.5^{\circ} \mathrm{W}-55 \mathrm{~W}^{\circ}\right)$ is shown in Figure 8. Estimated soil moisture values were higher than the climatological, and a consistency of its variability with the observed precipitation is noticed. The estimated soil moisture impact on the Bowen ratio $(\beta=\mathrm{H} / \mathrm{LE})$ is analyzed through the sensible and latent heating obtained from the two experiments, over the same precipitation analysis area (Figure 9). When the model is initialized with estimated soil moisture (EM), the latent heat flux is larger and the sensible heat is lower than when using the climatological value (CM). This difference can produce different responses in the boundary layer evolution. The boundary layer can be shallower, wetter and colder when using the estimated soil moisture rather than the climatological values. In this situation, boundary layer conditions are favorable to the convection process, because there is a reduction of the lifting condensation level (LCL) with increasing humidity [Mahrt and Ek, 1993].

[25] The smallest RMSE and ME values of SLP, Td and v were found in the results using the estimated soil moisture (Figure 10). The RMSE of the mean vertical profile for temperature, meridional and zonal winds at the three stations, indicate also that EM presents better results than the CM experiment (Table 2). The time average of the meridional wind profile for Resistência is shown in Figure 11. There are improvements of meridional wind at low levels when using more realistic soil moisture, reducing the tendency toward overestimated low-level northerly winds in the region. The northerly winds at low levels with maximum at $850 \mathrm{hPa}$ are closer to observed values in the EM experiment. Comparing to Figure 6, it is seen that the introduction of estimated soil moisture improved the meridional wind magnitude due to a better representation of the atmospheric fluxes. It is suggested that the convection intensification increases the roughness, reducing the lowlevel wind.

[26] The impact of soil moisture initialization can also be noted in the Quantitative Precipitation Forecast (QPF) analysis of ETS, BIAS, POD and FAR for 72-hour integrations (Figure 12). The information from ETS indicates an improvement over the results obtained using estimated soil moisture except at high precipitation thresholds. The precipitation bias indicates overestimated values, using the two soil moisture initializations, increasing with the rain intensity. For moderate to heavy rains, the EM initialization reduces the overestimation shown in the $\mathrm{CM}$ experiment, and for light rains, the biases are similar. The POD obtained from EM presents larger values than for CM, indicating improvements in the precipitation probability of detection. For all thresholds, except very low or very high values, FAR is smaller in EM than in CM, indicating less cases of false alarm.

[27] The evaluation of dynamic and thermodynamic variables and precipitation showed improvements in the model simulation results when considering a more realistic soil moisture field. Therefore integrations using this estimated field can provide better model forecasts, through the improvement of variables, mainly at low levels, where the LLJ 

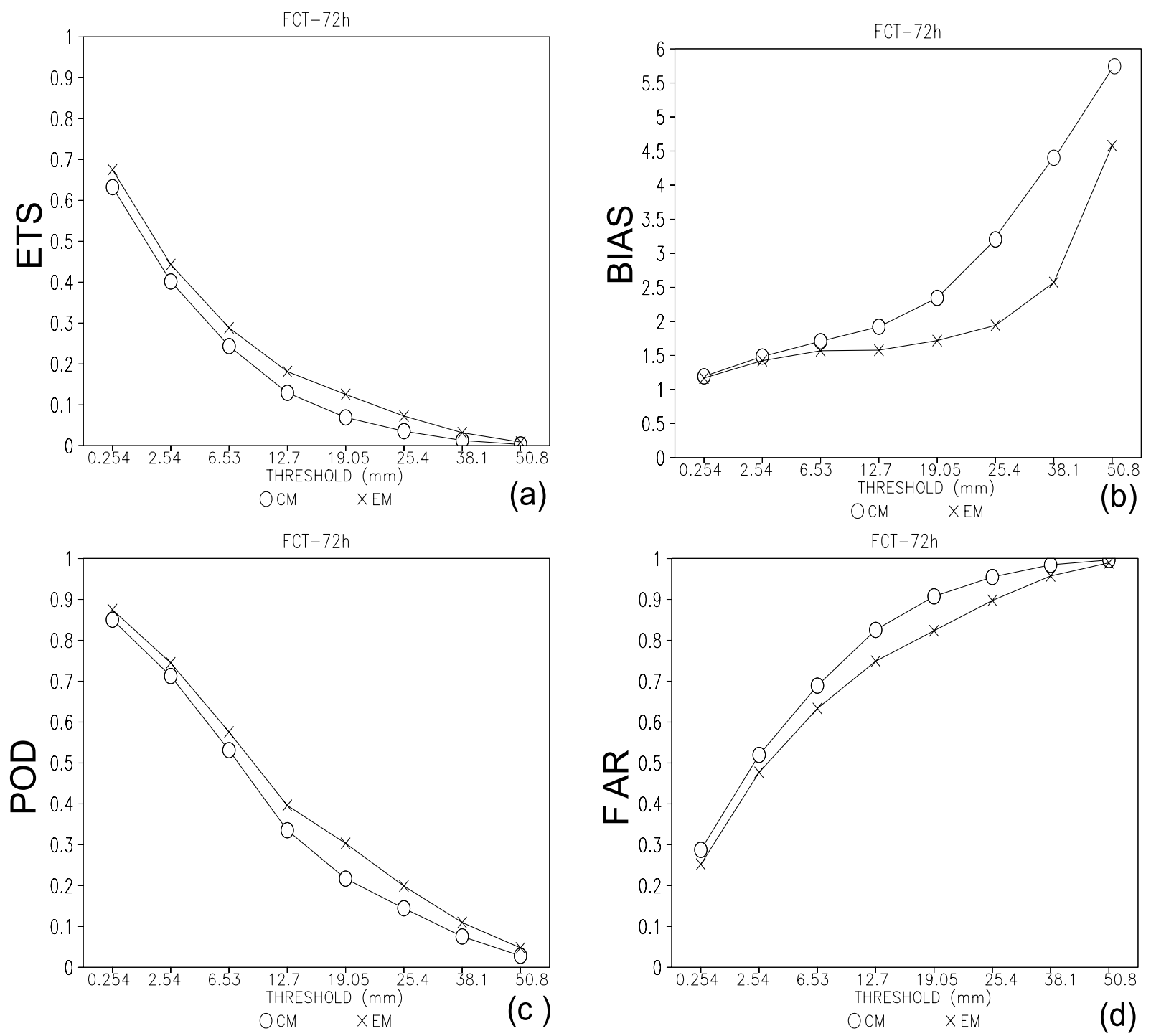

Figure 12. (a) ETS (without the bias influence), (b) BIAS, (c) POD, and (d) FAR for accumulated 48-72 hours precipitation simulations calculated using station data.

occurrence is an important feature for the MCS development. Thus the specific analysis of MCS occurrence in the next section is performed integrating the model with the estimated soil moisture.

\section{MCS Development Cases}

[28] In this section, the nonhydrostatic model version initialized with estimated soil moisture was integrated using two versions (BMJ and $\mathrm{KF}$ ) and $10 \mathrm{~km}$ horizontal $/ 38$ vertical levels in several cases of MCS occurrences. Each case having a mesoscale system can be identified in the 06:00 GMT satellite images in the northern sector (Figure 13a) and in the southern sector (Figure 14a). The spatial distribution of observed and simulated precipitation after 72 hours of integration (BMJ and KF) is seen in Figures 13b, 13c, 13d and Figures 14b, 14c, and 14d. The nocturnal development of this kind of system was mentioned in previous studies [e.g., Salio et al., 2007], and inspection of satellite images indicates that the mature stage occurs early in the morning.

[29] The model results with the BMJ scheme showed weaker precipitation than observations and a displacement of the systems compared to observations, in both sectors (Figures $13 \mathrm{c}$ and $14 \mathrm{c}$ ). Using the KF version, the systems were located close to the observation, with precipitation amounts more similar to observations than for the BMJ version (Figures 13d and 14d). In all MCS cases, a spatial average of precipitation in the development area at 72 hours' simulation ( $48-72 \mathrm{~h}$ accumulated), shows also the better results in KF than in BMJ (Figure 15). Precipitation amounts from KF are closer to observation, while the values are very small in BMJ. The model underestimate of precipitation compared to observations (TRMM data merged with gauge data) in MCS simulations may be related to the higher estimated precipitation from satellite measures (TRMM) than from gauge measures, as discussed in Appendix A. The present cases occurred in the spring, 

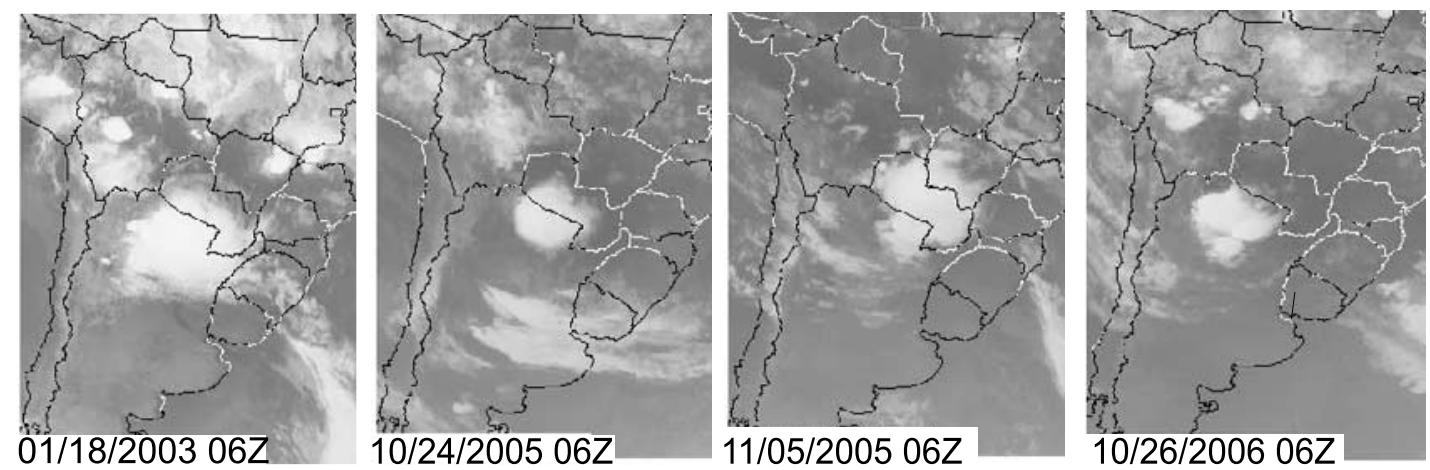

(a)
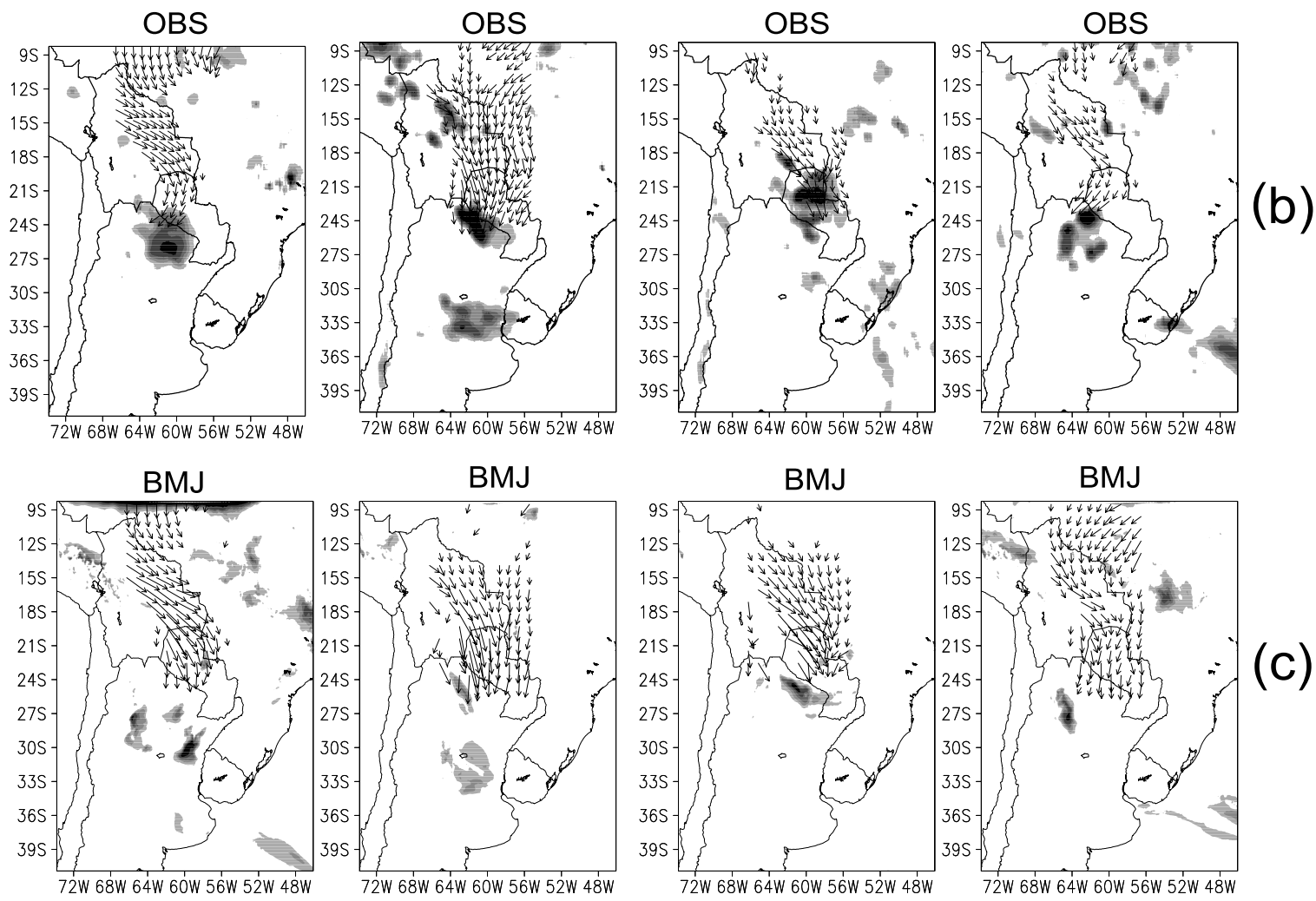

(c)

$\mathrm{KF}$
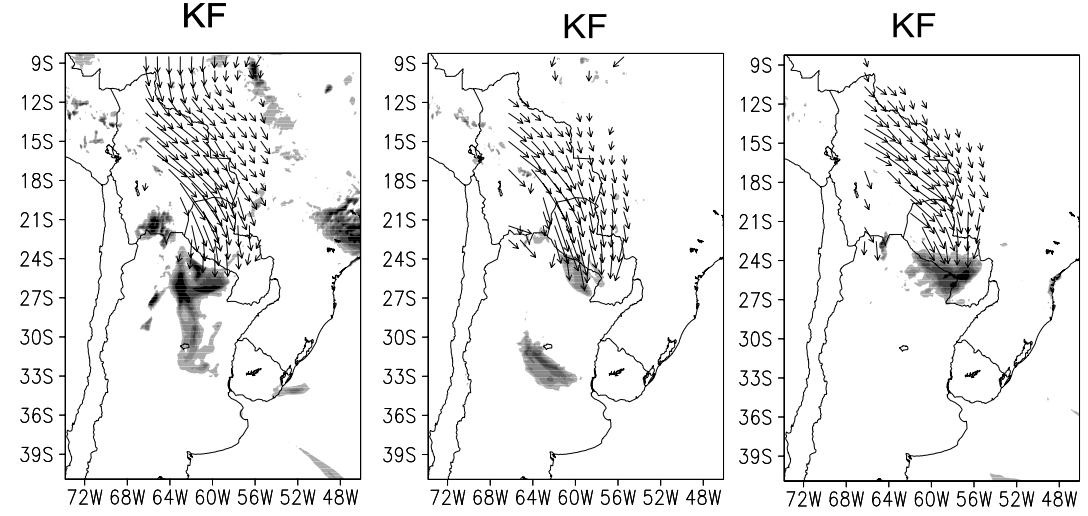

$\mathrm{KF}$

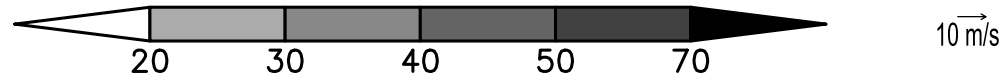

Figure 13. (a) Infrared satellite images at 06:00 GMT for cases of MCS development in northern sector $(01 / 18 / 2003 ; 10 / 24 / 2005 ; 11 / 05 / 2005,10 / 26 / 2006)$, (b) observed precipitation (mm/24 h), (c) Simulated precipitation (accumulated 48-72 hours) using BMJ version, and (d) simulated precipitation (accumulated $48-72$ hours) using KF version. Wind vectors at $850 \mathrm{hPa}$ are plotted when meridional northerly winds are greater than $5 \mathrm{~m} / \mathrm{s}$. 

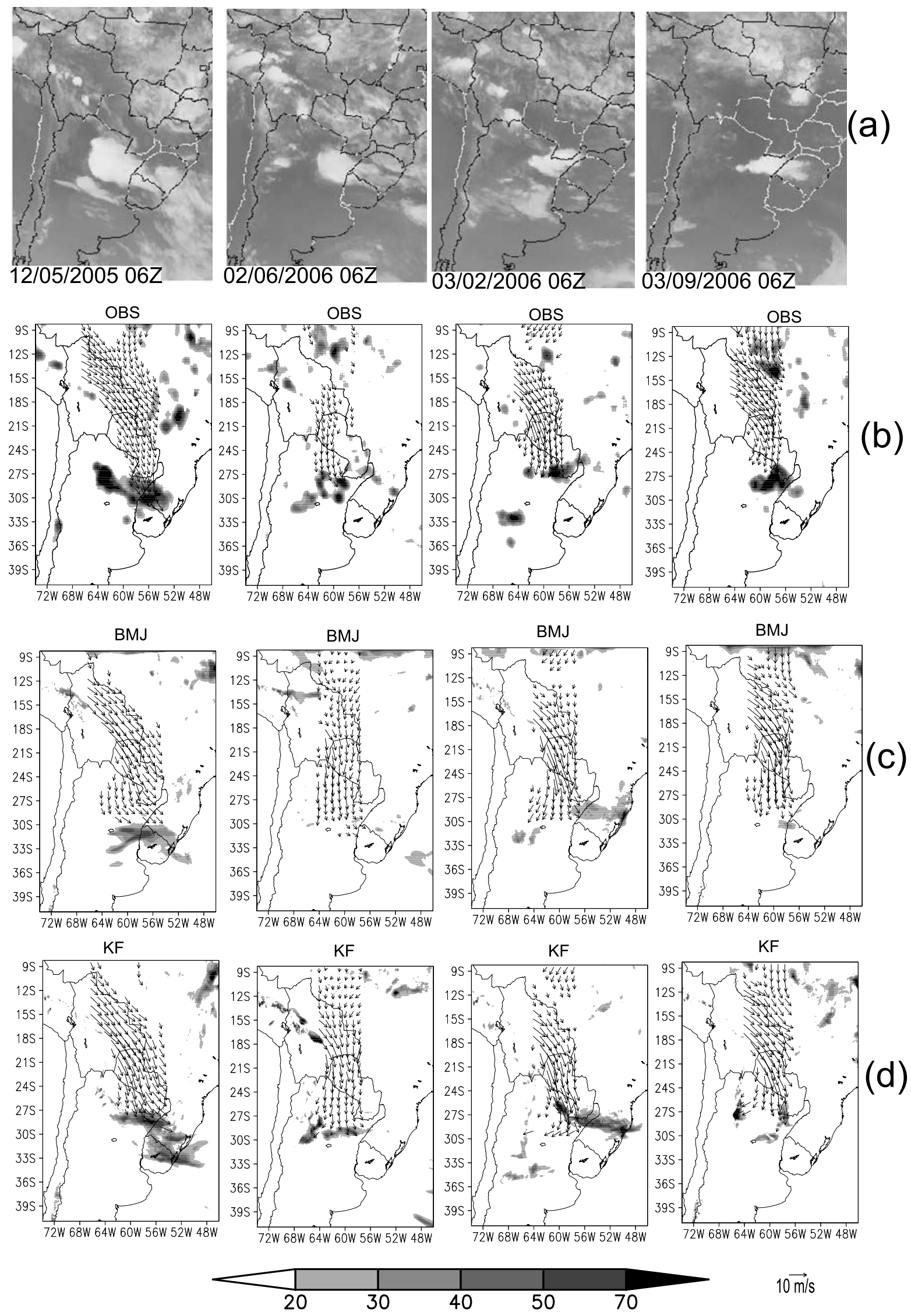

Figure 14 

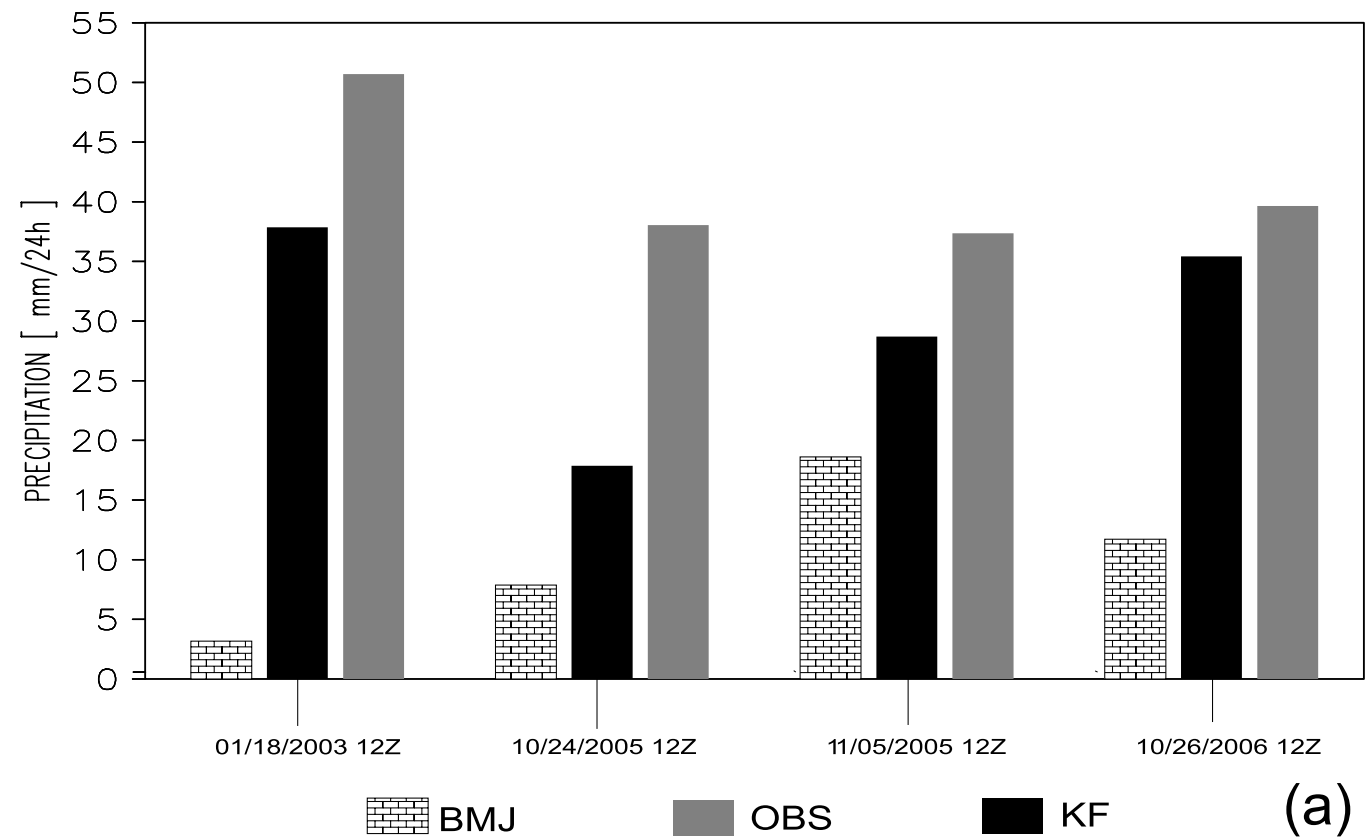

(a)

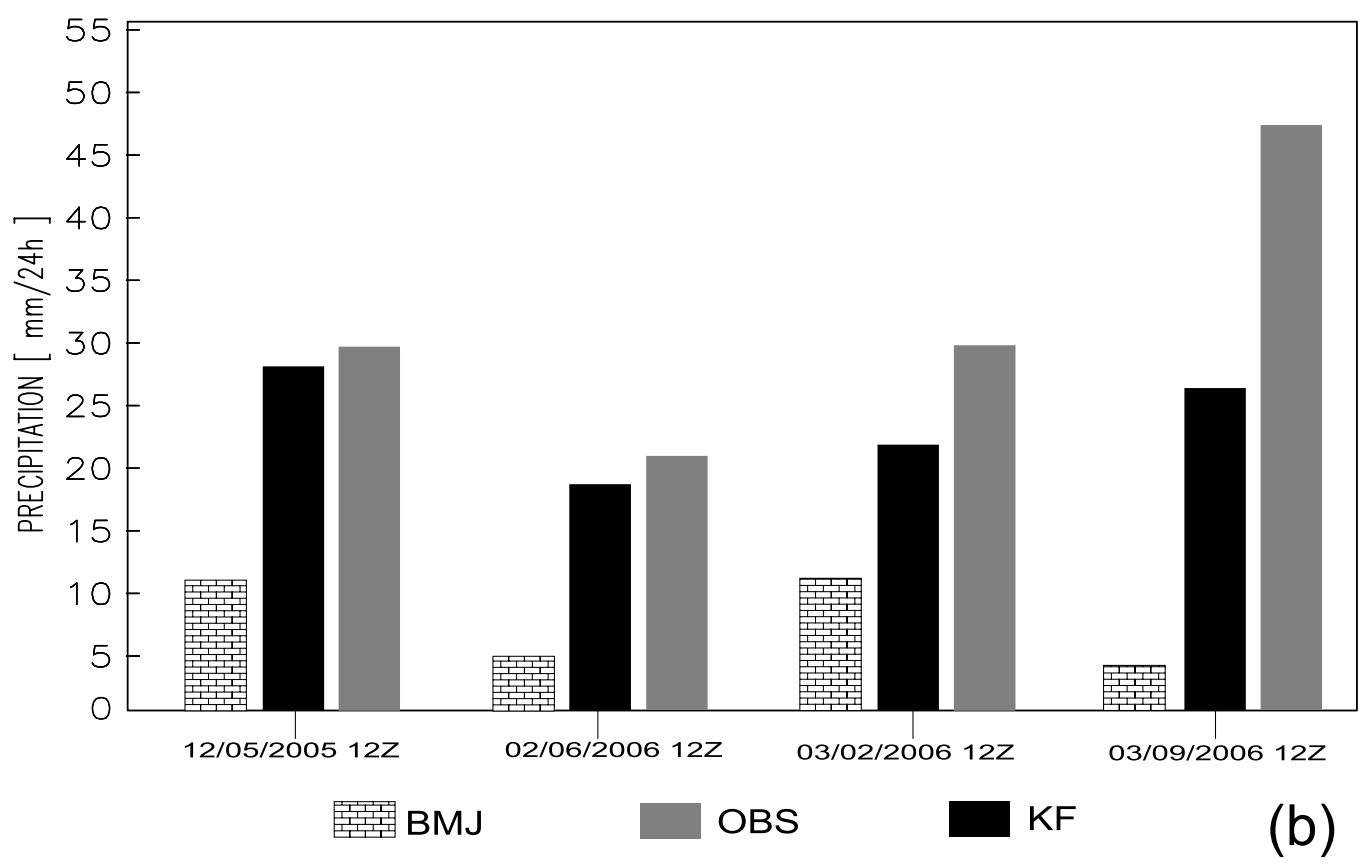

Figure 15. Spatial average in area $2^{\circ} \mathrm{X} 2^{\circ}$ centered over each MCS. OBS: $24 \mathrm{~h}$ observed accumulated precipitation, BMJ and KF simulations: $(48-72 \mathrm{~h})$ accumulated precipitation (a) northern sector and (b) southern sector.

summer and autumn. A high frequency of MCS over northern Argentina is observed during summer months associated with the LLJ occurrence [Salio et al., 2007]. The high frequency of MCS associated with the LLJ indicates the importance of the low-level conditions for their development. This feature is well detected by the model in Figure 13 and 14, which show the precipitation occurrence at the exit region of the maximum low-level

Figure 14. (a) Infrared satellite images at 06:00 GMT for cases of MCS development in southern sector (12/05/2005; 02/ 06/2006; 03/02/2006, 03/09/2006), (b) spatial distribution of observed precipitation ( $\mathrm{mm} / 24 \mathrm{~h}$ ), (c) simulated precipitation (accumulated 48-72 hours) using BMJ version, and (d) simulated precipitation (accumulated 48-72 hours) using KF version. Wind vectors at $850 \mathrm{hPa}$ are plotted when meridional northerly winds are greater than $5 \mathrm{~m} / \mathrm{s}$. 


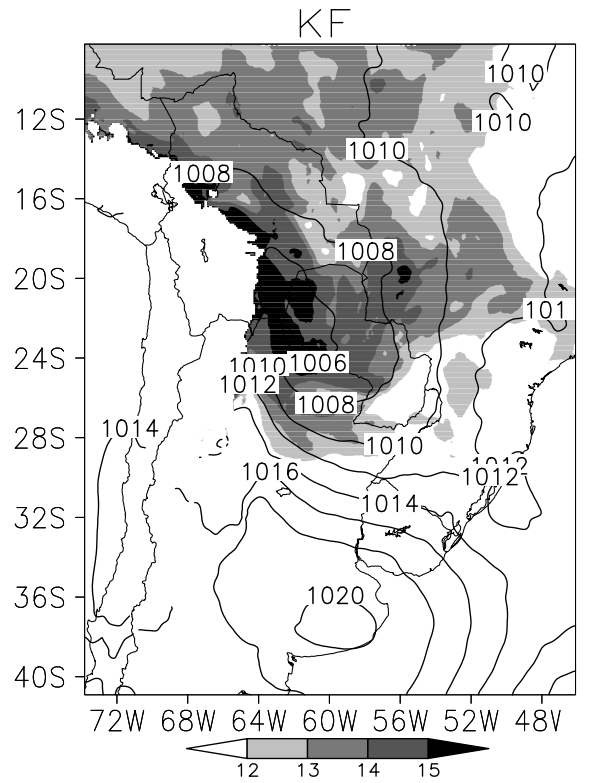

(a)

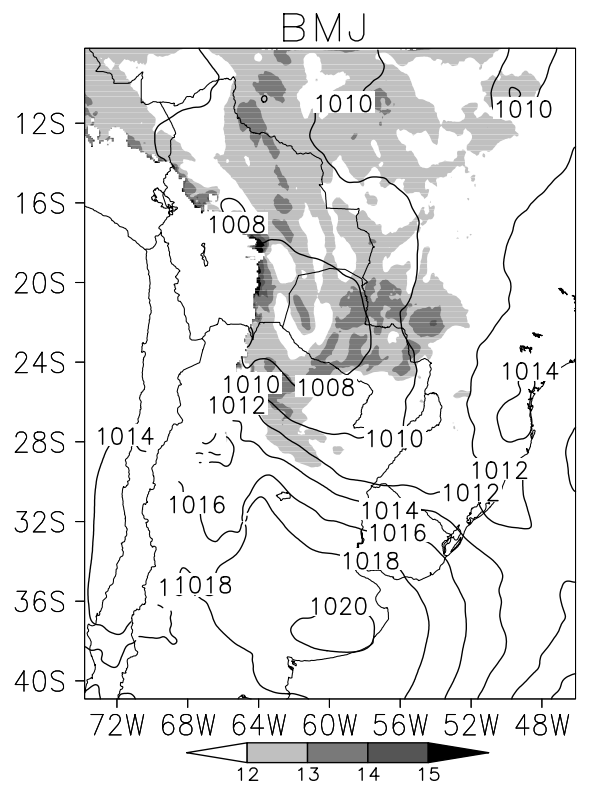

(b)

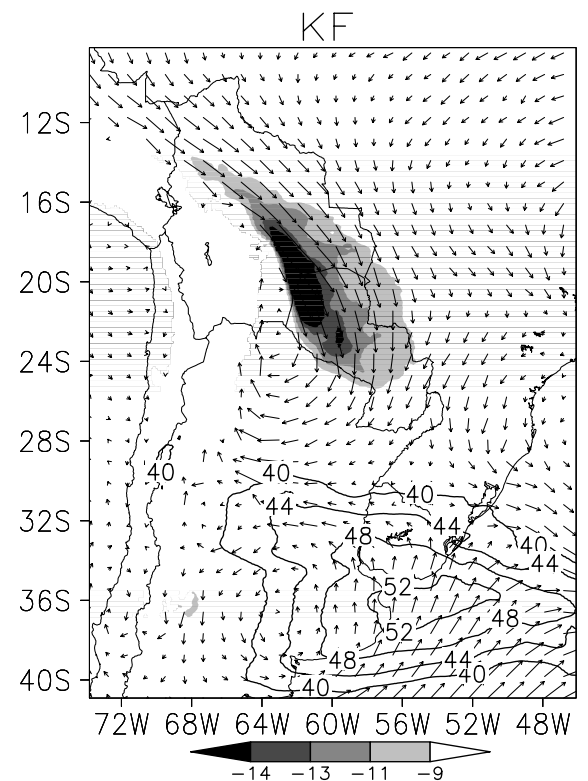

(c)

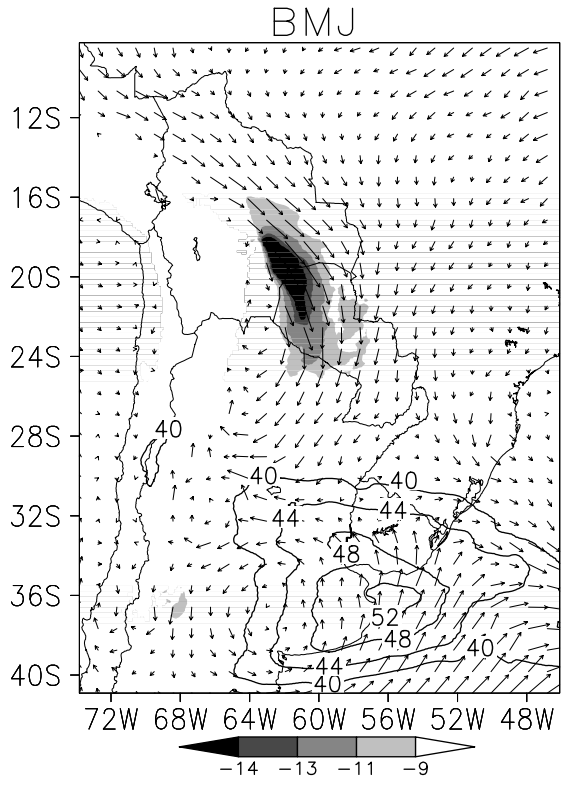

(d)

Figure 16. Sea-Level Pressure $(\mathrm{hPa})$ (contours) and specific humidity $\left((\mathrm{Kg} / \mathrm{Kg})^{*} 1000\right)$ at $850 \mathrm{hPa}$ (shaded), (a) KF, (b) BMJ. Wind vector and meridional component magnitude (m/s) at $850 \mathrm{hPa}$ (shaded). Wind magnitude at $250 \mathrm{hPa}$ (contour) (c) $\mathrm{KF}$, (d) BMJ (northern sector composite).

flow (represented by the wind vectors at $850 \mathrm{hPa}$ when the meridional northerly winds are greater than $5 \mathrm{~m} / \mathrm{s}$ ).

[30] A synoptic inspection of each case indicated similar features for the northern cases and for the southern cases, which allowed their separation into two composites. The Chaco Low was identified in the SLP field, deeper in KF than in $\mathrm{BMJ}$, and the humidity at $850 \mathrm{hPa}$ was higher in $\mathrm{KF}$ than in BMJ, in the tropical and subtropical region, mainly to the east of Andes (Figures 16a and 16b). The meridional wind at $850 \mathrm{hPa}$ showed the LLJ affecting a wider area in $\mathrm{KF}$ than in BMJ over southern Bolivia and Paraguay, which are the LLJ-preferred regions (Figures 16c and 16d). Vertical cross sections of meridional wind confirmed the presence of the LLJ in these cases (Figure 17). The strong north-south temperature gradient at low levels was consistent with the jet stream at high levels. The upper level jet stream magnitude reaches values above $50 \mathrm{~m} / \mathrm{s}$ over mouth of the La Plata river in both versions, but the jet core extension is larger in KF than in BMJ (Figures 16c and 16d). In the two versions, the composites show the jet stream in a favorable position for ascent at the equatorward side of the jet entrance. However, the northerly flow advecting the 

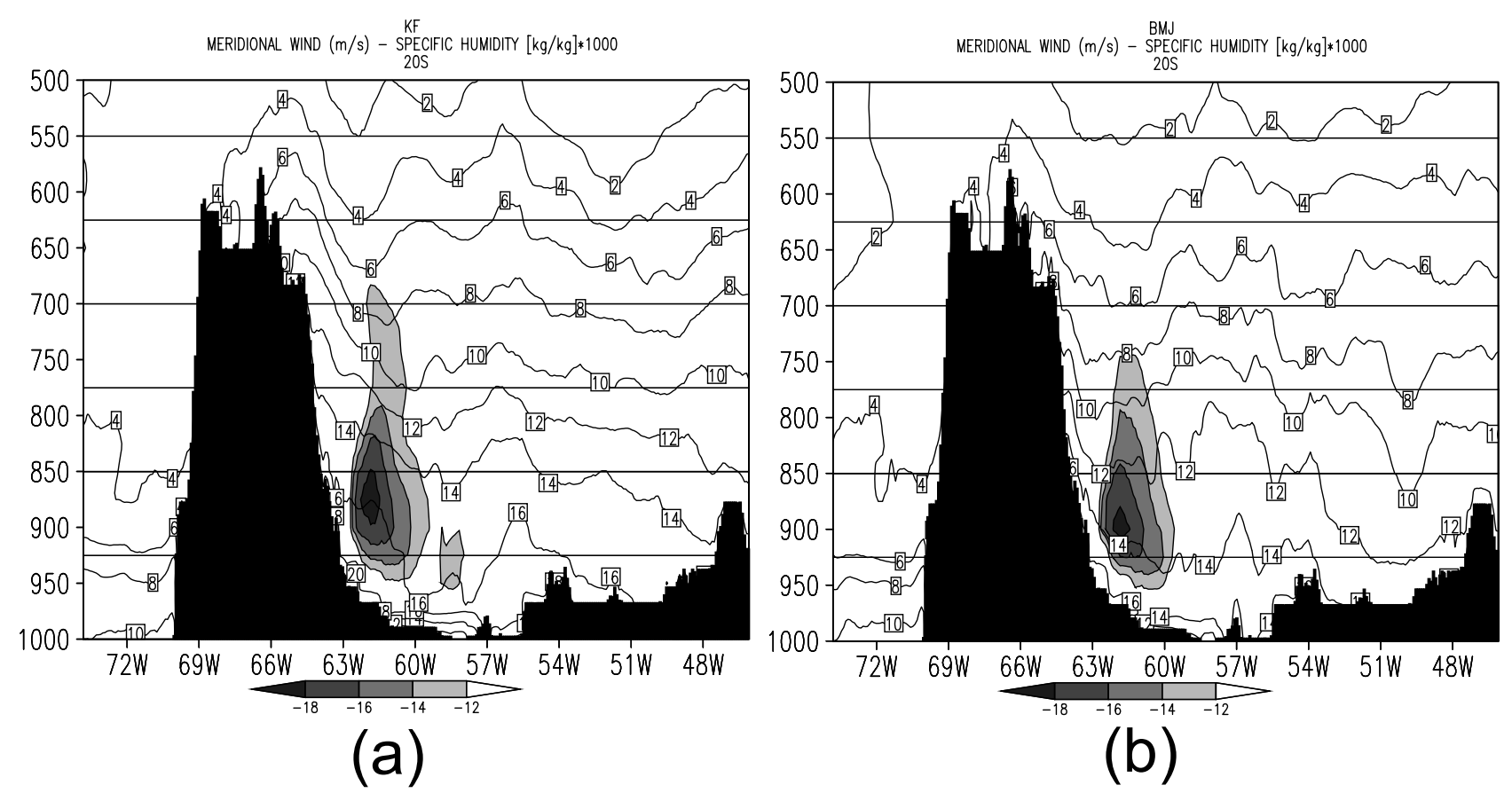

Figure 17. Vertical cross-section of meridional wind (shaded) and specific humidity (contour) at $20^{\circ} \mathrm{S}$ for the northern sector composite. (a) KF, (b) BMJ.

highest humidity from the tropical and subtropical latitudes in the KF version indicates better conditions for the MCS development than the BMJ version. The differences between the two versions for the cases that occurred in the southern sector had characteristics similar to those in the northern sector (not shown).

[31] Skill indexes for precipitation, at 72 hours simulation for the eight MCS cases are shown in Figure 18. The indexes were calculated using station data in the areas of MCS occurrence, in the northern sector $\left(28^{\circ} \mathrm{S}-20^{\circ} \mathrm{S}\right.$; $\left.67^{\circ} \mathrm{W}-56^{\circ} \mathrm{W}\right)$ and in the southern sector $\left(33^{\circ} \mathrm{S}-25^{\circ} \mathrm{S}\right.$; $\left.64^{\circ} \mathrm{W}-53^{\circ} \mathrm{W}\right)$. ETS shows a better skill for the KF version for all thresholds, except for very light or no rain. BIAS indicates similar results from light or no-rain categories for both versions, with simulations close to observations. Different BIAS for the two versions is seen for moderate to heavy rains, but KF shows better performance, with smaller underestimated values than BMJ. POD and FAR indexes show improvements using KF in all categories. Therefore these analyses for specific MCS occurrence indicated the improvement of heavy precipitation forecasts using the KF convection scheme, consistent with the statistical analysis with thresholds in section 3.2.

\section{Summary and Conclusion}

[32] The performance of the regional Eta model with different configurations was evaluated in the preferred region of MCS occurrence, during the SALLJEX. Additionally, eight MCS development cases were analyzed through model simulation. Results of the nonhydrostatic and hydrostatic model versions showed improvements using the NH version when there was precipitation in small areas, as in cases of MCS occurrence. However, as the NH version processing time is very high with the computer system we used (twice that needed by the $\mathrm{H}$ version), the $\mathrm{H}$ version was applied to test convection and soil moisture for the same period. In simulations for MCS cases, the NH version was applied.

[33] The results showed that the convection scheme impact on model results depends on the area size and duration of analysis. If the error analysis of a variable is calculated over a large area, where there are small regions of strong and large regions of weak vertical motion, the final result is favorable to BMJ scheme, which shows better skill for light rains. In the same way, if the error analysis is calculated in a specific location, but for a long period, when strong and weak vertical motion can occur, the result is also favorable to the BMJ scheme. However, in specific MCS cases, which are characterized by episodes of strong ascent in a limited convective area, the KF scheme gives the best results. This behavior is related to the characteristic of each scheme. Entraining/detraining air to and from convective clouds and the moist updrafts and downdrafts, introducing more humidity in the atmosphere are explicitly represented in $\mathrm{KF}$. In the BMJ scheme, precipitation is proportional to the integrated water between the large-scale moisture profile and a reference profile. Thus BMJ scheme seems to be more adequate to convection in large areas rather than to convection associated with a concentration of convective clouds as in a MCS. Better results were obtained using estimated soil moisture rather than climatological values, through its influence on surface fluxes.

[34] The main features associated with the best MCS simulation in KF were also related to the atmospheric fields obtained from each version. In the specific cases, KF produced more atmospheric humidity, a stronger upper level jet, deeper Chaco Low, better representation of the LLJ 

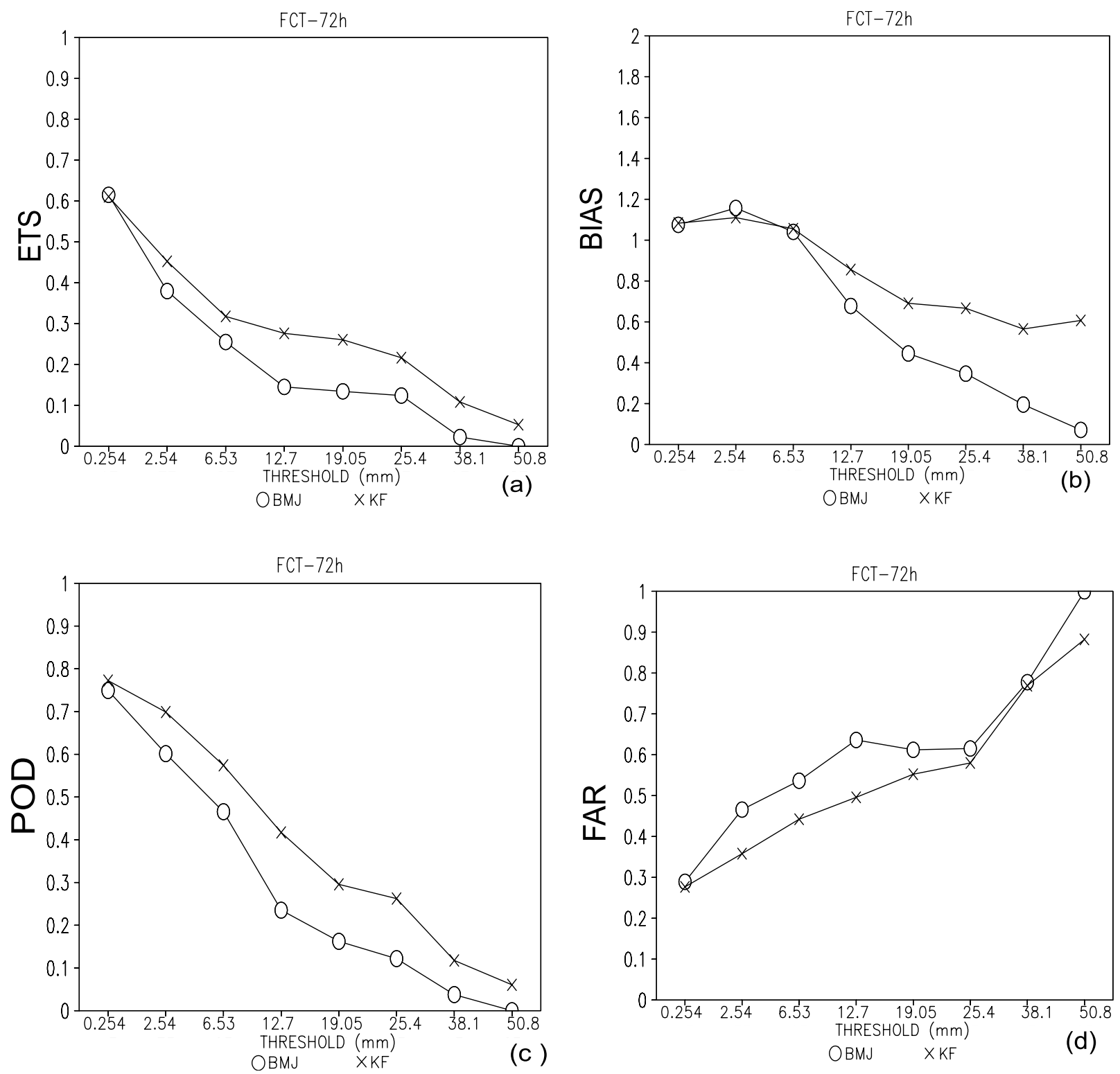

Figure 18. (a) ETS (without the bias influence), (b) BIAS, (c) POD, and (d) FAR for accumulated 48-72 hours precipitation simulations calculated using station data in both northern and southern sectors.

influence, conditions that were crucial to a better simulation of MCS. A combination of the two features (entrance region of the upper level jet stream which forces a secondary circulation [Salio et al., 2007], and LLJ exit with the convergence of humidity flux from the north) positioned at the same region, were the ingredients for the MCS development. Therefore the best configuration of the Eta model for the simulation of MCS over northern Argentina was the version using NH, KF and EM. The model with these configurations was able to simulate the precipitation and the main atmospheric characteristics associated with the MCS development, such as the upper level jet, LLJ, humidity and associated mechanisms for ascent motion, 72 hours in advance. A detailed analysis of the synoptic situation, the diurnal cycle and the influence of a local circulation on MCS development indicated also the model ability to simulate these additional features, which will be shown in a further study.

\section{Appendix A: Evaluation of TRMM Estimated Precipitation}

[35] An average of observed precipitation above $10 \mathrm{~mm}$ at several ground stations located in the MCS development region (4 cases for each sector) was compared to an average of TRMM data at each grid point corresponding to the station location (Figures A1 and A2). In six cases TRMM data overestimated the observed rainfall. This feature is associated with the method utilized to obtain the precipitation values, which takes into account the cloud top temperature (in this case very high and cold tops) and does not consider the evaporated fraction of the rainfall before it reaches the ground. Therefore the model simulated precip- 


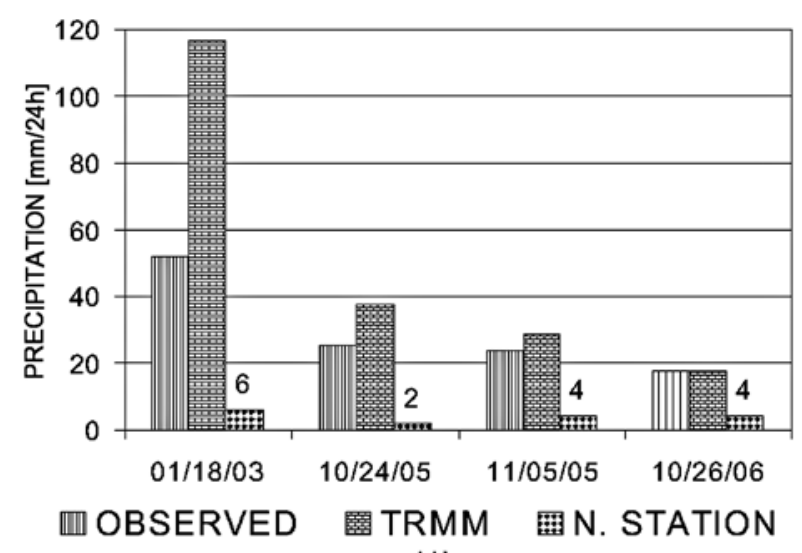

(1)

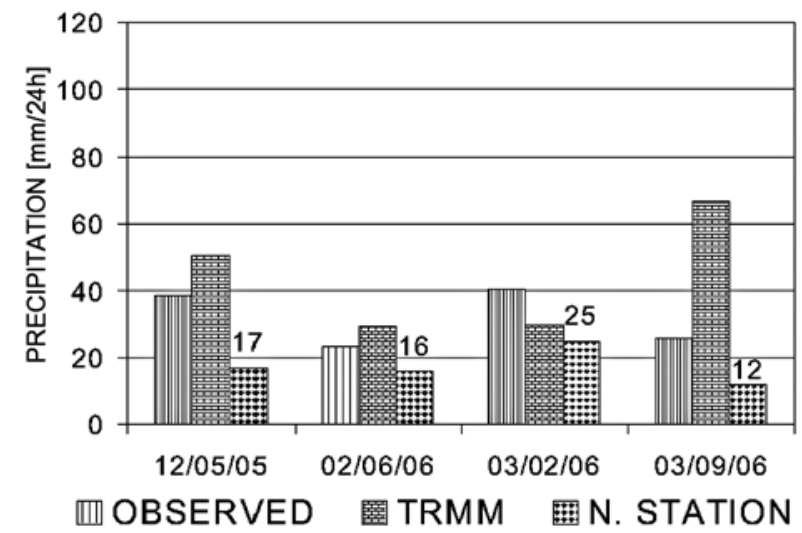

(2)

Figure A1. Spatial average of precipitation above $10 \mathrm{~mm} /$ $24 \mathrm{~h}$ measured in pluviometers and obtained from TRMM, for the MCS cases occurred in the (1) northern sector and (2) southern sector. The number of measures is indicated in the third column.

itation might present less underestimated values that those shown when compared to the TRMM data.

[36] Acknowledgments. The authors are grateful to the FAPESPSALLJEX project (01/13816), FAPESP-Serra do Mar project (04/09469-0), and $\mathrm{CNPq}$ for research support.

\section{References}

Arakawa, A., and V. R. Lamb (1977), Computational design of the basic dynamical process of the UCLA general circulation model, Methods Comput. Phys., 17, 173-265.

Baldwin, M. E., and J. S. Kain (2006), Sensitivity of several performance measures to displacement error, bias, and Event Frequency, Weather Forecast., 21(4), 636-648.

Betts, A. K., and M. J. Miller (1986), A new convective adjustment scheme. Part II: Single column tests using GATE wave, BOMEX, ATEX and Arctic air-mass data sets, Q. J. R. Meteorol. Soc., 112, 693-709.

Caplan, P., J. Derber, W. Gemmill, S. Y. Hong, H. L. Pan, and D. Parrish (1997), Changes to the 1995 NCEP operational medium-range forecast model analysis-forecast system, Weather Forecast., 12, 581-594.

Cavalcanti, I. F. A., and D. Herdies (2004), Data assimilation study using SALLJEX data, Exchanges, 9(1), 23-25.

de Gonçalves, L. G. G., W. J. Shuttleworth, S. C. Chou, Y. Xue, P. R. Houser, D. L. Toll, J. Marengo, and M. Rodell (2006), Impact of different initial soil moisture fields on Eta model weather forecasts for South America, J. Geophys. Res., 111, D17102, doi:10.1029/2005JD006309.

Dudhia, J., D. Gill, Y. Guo, K. Manning, W. Wang, and J. Chiszar (2000), Mesoscale Modeling System Tutorial Class Notes and User's Guide, MM5 Modeling System Version 3, PSU/NCAR.
Ek, M. B., K. E. Mitchell, Y. Lin, E. Rogers, P. Grunmann, V. Koren, G. Gayno, and J. D. Tarpley (2003), Implementation of Noah land surface model advances in the National Centers for Environmental Prediction operational mesoscale Eta model, J. Geophys. Res., 108(D22), 8851, doi:10.1029/2002JD003296.

Fells, S. B., and M. D. Schwarzkopf (1975), The simplified exchange approximation. A new method for radiative transfer calculations, J. Atmos. Sci., 32, 1475-1488.

Fox, D. G. (1981), Judging air quality model performance, Bull. Am. Meteorol. Soc., 62, 599-609.

Gadd, A. J. (1978), A split explicit integration scheme for numerical weather prediction, Q. J. R. Meteorol. Soc., 104, 569-582.

Gevaerd, R., and S. R. Freitas (2006), Estimativa operacional da umidade do solo para iniciação de modelos de previsão numérica da atmosfera Parte I: descrição da metodologia e validação, Rev. Bras. Meteorol., 21(3a), 59-73.

Gochis, D. J., W. Shuttleworth, and Z. Yang (2002), Sensitivity of the modeled North American Monsoon Regional climate to convective parameterizations, Mon. Weather Rev., 130, 1282-1298.

Huffman, G. J., R. F. Adler, B. Rudolf, U. Schneider, and P. R. Keehn (1995), Global precipitation estimates based on a technique for combining satellite-based estimates, rain gauge analysis, and NWP model precipitation information, J. Climate, 8, 1284-1295.

Janjic, Z. I. (1994), The step-mountain eta coordinate model: Further developments of the convection, viscous sublayer, and turbulence closure schemes, Mon. Weather Rev, 122, 927-945.

Kain, J. S., and J. M. Fritsch (1992), The role of the convective "trigger" function in numerical forecasts of mesoscale convective systems, Meteor. Atmos. Phys., 49, 93-106.

Kato, T., and K. Saito (1995), Hydrostatic and non-hydrostatic simulation of moist convection: The applicability of hydrostatic approximation to a high-resolution model, J. Meteorol. Soc. Jpn., 73, 59-77.

Klausmann, A. M., F. Robe, M. Phadnis, and J. Scire (2002), Sensitivity of Explicitly Simulated Convection to Mother Domain Cumulus Parameterization Schemes, Twelfth PSU/NCAR Mesoscale Model Users'Workshop - NCAR - June 24-25.

Lacis, A. A., and J. E. Hansen (1974), A parameterization of the absorption of solar radiation in earth's atmosphere, J. Atmos. Sci., 31, 118-133.

Mahrt, L., and M. Ek (1993), Spatial variability of turbulent fluxes and roughness lengths in HAPEX-MOBILHY, Boundary - Layer Meteorol., $65,381-400$

McCumber, M. C., and R. A. Pielke (1981), Simulation of the effects of surface fluxes on heat and moisture in a mesoscale numerical model. Part I: Soil Layer, J. Geophys. Res., 86, 9929-9938.

Mellor, G. L., and T. Yamada (1982), Development of a turbulence closure models for geophysical fluid problems, Rev. Geophys. Space Phys., 20, $851-875$.

Mesinger, F. (1984), A blocking for representation of mountains in atmospheric models, Riv. Meteorol. Aeronaut., 44, 195-202.

Mesinger, F., and K. Brill (2004), Bias normalized precipitation scores. Preprints, 17th Conf. on Probability and Statistics, Seattle, WA, Am. Meteorol. Soc., CD-ROM, J12.6.

Mesinger, F., and R. E. Treadon (1995), "Horizontal" reduction of pressure to sea level: Comparison against the NMC's shuell method, Mon. Weather Rev., 123, 59-68.

Mesinger, F., Z. I. Janjic, S. Nickovic, D. Gavrilov, and D. G. Deaven (1988), The step-mountain coordinate: Model description and performance for cases of alpine lee cyclogenesis and for a case of an appalachian redevelopment, Mon. Weather Rev., 116, 1493-1518.

Pielke, R. A. (2002), Mesoscale Meteorological Modeling, 612 pp., Elsevier, New York.

Rozante, J. R., and I. F. A. Cavalcanti (2006), Eta model experiments during the SALLJEX period, in 8th Southern Hemisphere International Conference on Meteorology and Oceanography, 2006, Foz do Iguaçu.

Saito, K., et al. (2006), The Operational JMA Nonhydrostatic Mesoscale Model, Mon. Weather Rev. 134, 1266-1298.

Salio, P., M. Nicolini, and E. J. Zipser (2007), Mesoscale convective systems over Southeastern South America and their relationship with the South American Low Level Jet, Mon. Weather Rev., 135, 1290-1309.

Saulo, C., M. Nicolini, and S. C. Chou (2000), Model characterization of the South American low-level flow during the 1997-1998 spring-summer season, Clim. Dyn., 16, 867-881.

Segal, M., R. Arritt, C. Clark, R. Rabin, and J. Brown (1995), Scaling evaluation of the effect of surface characteristics on potential for deep convection over uniform terrain, Mon. Weather Rev., 123, 383-400.

Sellers, P. J., W. J. Shuttleworth, J. L. Dorman, A. Dalcher, and J. M. Roberts (1989), Calibrating the simple biosphere model (SiB) for Amazonia tropical forest using field and remote sensing data. part I: Average calibration with field data, J. Appl. Meteorol., 28, 727-759. 
Seluchi, M. E., and S. C. Chou (2001), Ajuste del Esquema Convectiv o de Betts-Miller en el Modelo Regional Eta/CPTEC, Meteorológica, 5, 4556.

Vera, C., et al. (2006), The South American Low-Level Jet Experiment (SALLJEX), Bull. Am. Meteorol. Soc., 86(1), 63-77.

Vernekar, A., B. Kirtman, and J. M. Fennessy (2003), Low-level jets and their effects on the South American summer climate as simulated by the NCEP Eta Model, J. Climate, 16, 297-311.

Viterbo, P., and A. C. Beljaars (1995), An improved land surface parameterization scheme in the ECMWF model and its validation, $J$. Climate, 8 , $2716-2748$.

Wang, W., and N. L. Seaman (1997), A comparison study of convective parameterization schemes in a mesoscale model, Mon. Weather Rev., 125, $252-278$.
Willmott, C. J., C. M. Rowe, and Y. Mintz (1985), Climatology of the terrestrial seasonal water cycle, J. Climatol., 5, 589-606.

Yang, M. J., and Q. C. Tung (2003), Evaluation of rainfall forecasts over Taiwan by four cumulus parameterization schemes, J. Meteorol. Soc. Jpn., 81, 1163-1183.

Zipser, E., P. Salio, and M. Nicolini (2004), Mesoscale convective systems activity during SALLJEX and the relationship with SALLJ events, Exchanges, 9(1), 14-18.

I. F. A. Cavalcanti and J. R. Rozante, Center for Weather Forecast and Climate Studies CPTEC/INPE, Rodovia Presidente Dutra KM 40, Cachoeira Paulista, S.P., CEP 12 630-000 Brazil. (rozante@) cptec.inpe.br) 